\title{
Spirocerca lupi infection in the dog: A review
}

\author{
Liesel L. van der Merwe' ${ }^{\text {a, }}$, Robert M. Kirberger ${ }^{a}$, Sarah Clift ${ }^{\mathrm{a}}$, Mark Williams ${ }^{\mathrm{a}}$, \\ Ninette Keller ${ }^{\mathrm{a}}$ and Vinny Naidoo ${ }^{\mathrm{a}}$ \\ ${ }^{a}$ Department of Companion Animal Clinical Studies, Faculty of Veterinary Science, \\ University of Pretoria, Gauteng 0110, South Africa
}

\begin{abstract}
Spirocercosis is a disease occurring predominantly in Canidae, caused by the nematode Spirocerca lupi. Typical clinical signs are regurgitation, vomiting and dyspnoea. The lifecycle involves an intermediate (coprophagous beetle) and a variety of paratenic hosts. Larvae follow a specific migratory route, penetrating the gastric mucosa of the host, migrating along arteries, maturing in the thoracic aorta before eventually moving to the caudal oesophagus. Here the worm lives in nodules and passes larvated eggs which can be detected using zinc sulphate faecal flotation. Histologically, the mature oesophageal nodule is composed mostly of actively dividing fibroblasts.

Spirocerca lupi-associated oesophageal sarcomas may occur and damage to the aorta results in aneurysms. A pathognomonic lesion for spirocercosis is spondylitis of the thoracic vertebrae. Primary radiological lesions include an oesophageal mass, usually in the terminal oesophagus, spondylitis, and undulation of the aortic border. Contrast radiography and computed tomography are helpful additional emerging modalities. Oesophageal endoscopy has a greater diagnostic sensitivity than radiography. Endoscopic biopsies are not sensitive for detecting neoplastic transformation. Doramectin is the current drug of choice, effectively killing adult worms and decreasing egg shedding. Early diagnosis of infection is still a challenge and to date no ideal regimen for prophylaxis has been published.
\end{abstract}

\section{Article Outline}

\author{
Introduction \\ Distribution \\ Life-cycle \\ Pathogenesis and pathology \\ Neoplastic transformation \\ Clinical signs \\ Diagnosis \\ Faecal flotation \\ Clinical pathology \\ Serology \\ Diagnostic imaging
}


Oesophagoscopy

Treatment

Medical treatment

Surgical and chemotherapeutic treatment

Prevention

Conclusions

Acknowledgements

References

\section{Introduction}

Spirocercosis is a disease caused by the nematode Spirocerca lupi which has a variety of clinical presentations ([Dvir et al., 2001], [Lobetti, 2000] and [Mazaki-Tovi et al., 2002]). $S$. lupi is found worldwide especially in tropical and subtropical regions. This nematode has been found in many species, but affects mostly carnivores, especially Canidae ([Dvir et al., 2001], [Lobetti, 2000] and [Mazaki-Tovi et al., 2002]). Clinical signs are mostly due to the migration and persistence of the larvae or adult worms within the host and secondary bacterial infections. Diagnosis in the early stages can be challenging and, unfortunately, most animals are only diagnosed once advanced disease is present. The most commonly reported clinical signs are regurgitation and vomiting ([Mazaki-Tovi et al., 2002] and [Ranen et al., 2004]). The distribution, life-cycle, pathogenesis and pathology, clinical signs, diagnosis, treatment and prevention of $S$. lupi will be discussed in this review.

\section{Distribution}

Spirocerca lupi is a nematode with a worldwide distribution in regions with a warm climate. The majority of reports are from Israel (Mazaki-Tovi et al., 2002), Greece (Mylonakis et al., 2001), Turkey, India (Ramachandran et al., 1984), Pakistan (Anataraman and Krishna, 1966), the southern United States (Dixon and McCue, 1967), Brazil (Oliviera-Sequeira et al., 2002), Kenya (Brodey et al., 1977) and South Africa (Lobetti, 2000).

In Israel, the majority (62\%) of infections are diagnosed in winter whereas no seasonality was found in South Africa ([Lobetti, 2000] and [Mazaki-Tovi et al., 2002]). Spirocercosis is an emerging disease in Tel Aviv with a sevenfold increase in cases in nine years and the disease is more prevalent in urban areas, in contrast to information from the USA where the disease is more common in rural areas (Mazaki-Tovi et al., 2002). The most important factors affecting prevalence are proximity to intermediate and paratenic (transport) hosts and the population density of infected and intermediate hosts. Prevalence data can, however, be misleading and must be interpreted with reference to the dog population sampled: stray animals versus pets, the region of the country sampled, urban versus rural and the method of diagnosis (necropsy versus faecal flotation).

Prevalence data also changes over time in a specific region. These factors have been 
clearly demonstrated in the various studies performed in Kenya ([Brodey et al., 1977], [Kagira and Kanyari, 2001], [Murray, 1968] and [Wandera, 1976]). The variability in prevalence is attributed to degree of rural development, utilisation of pesticides, efforts at disease control and changing nutritional habits. Faecal surveys have shown prevalences of $57 \%$ in Sierra Leone (Kamara, 1964), 56\% in Kenya (Brodey et al., 1977), 23\% in India (Chandrasekharon et al., 1958), 33.5-47\% in the southern United States (Dixon and McCue, 1967) and 5\% in Reunion Island (Prunaux and Guignard, 1991). Prevalence based on necropsy results are $23.5 \%$ in India (Ramachandran et al., 1984), 3-78\% in Kenya and $13 \%$ in South Africa (Minnaar et al., 2002). In a necropsy report from Kenya the prevalence was $85 \%$ in stray dogs and only $38 \%$ in client owned dogs (Brodey et al., 1977).

There is no sex or age predilection for infection although due to the nematode lifecycle, dogs under 6 months of age, although infected, have not yet developed oesophageal disease and the classic clinical signs ([Fox et al., 1988] and [Wandera, 1976]). There does however seem to be a breed predilection. Hounds and large breed dogs have a higher incidence of $S$. lupi than other breeds ([Bailey, 1963] and [Lobetti, 2000]). A study conducted in Greece showed a disease prevalence of $10 \%$ in 260 privately owned dogs (Mylonakis et al., 2001). However, the prevalence in subgroups differed markedly: the prevalence in trace hunting dogs was $21 \%$, scent hunting dogs $5 \%$ and pets $0 \%$. This indicates a definite impact of lifestyle and exposure to the intermediate or paratenic host on disease transmission. German Shepherd dogs have been overrepresented in several studies ([Dvir et al., 2001] and [Ramachandran et al., 1984]). A study from Brazil determined that poodles were predisposed (Oliviera-Sequeira et al., 2002) and in Israel the Labrador Retriever seems predisposed (Mazaki-Tovi et al., 2002). Spirocercosis has also been reported in domestic cats showing clinical signs of vomiting (Mense et al., 1992) and wild Felidae ([Brodey et al., 1977] and [Upadhye et al., 2001]).

\section{Life-cycle}

The lifecycle of $S$. lupi involves intermediate and paratenic hosts. The adult worms are found coiled within nodules in the oesophageal wall. S. lupi eggs containing larvae (L1) are passed from the oesophagus through the gastrointestinal tract and into the faeces or may be shed in the vomitus. A variety of species of coprophagous beetles act as intermediate hosts. Eggs are ingested by the intermediate host and the larvae encyst within the tissues and develop to infectivity (L3) within 2 months. The beetle is ingested by the final host (dog) or a paratenic host.

Infective larvae are capable of utilising a great variety of paratenic hosts including poultry, wild birds, lizards, rodents, hedgehogs and rabbits (Fox et al., 1988). The larvae can also transfer from one paratenic host to another (Fox et al., 1988). In the paratenic hosts the third stage larvae excyst and then re-encyst within host tissue where they appear as small $(0.5 \times 0.4 \mathrm{~mm})$ white nodules (Sen and Anataraman, 1971). The distribution of the L3 within sthe paratenic host varies between species (Sen and Anataraman, 1971). In the lizard, Calotes versicolor, the larvae were found throughout the subcutis, thoracic muscles and stomach wall and averaged 54.7 (2-600) per specimen. In the grey shrew, 
Suncus murinus, cysts were mainly found in the stomach wall and were fewer in number, averaging 25.8 per specimen. In poultry and wild birds larvae develop in the wall of the crop ([Bhatia et al., 1979] and [Brodey et al., 1977]). Poultry offal has been shown to be a major source of infection in Kenya (Brodey et al., 1977) and the southern United States (Dixon and McCue, 1967). In Madras, India, 88.5\% of lizards were found to be infected (Anataraman and Krishna, 1966).

The final host becomes infected by ingesting either the infected beetle or paratenic host. The paratenic host is a more probable source of infection for carnivores (Sharpilo, 1983). The L3 excyst in the stomach and penetrate the gastric mucosa within $2 \mathrm{~h}$ of ingestion, evidenced by petechial haemorrhages and erosions on the mucosa (Hu and Hoeppli, 1936). The gastric serosal surface is reached within $24-48 \mathrm{~h}$, resulting again in haemorrhage and inflammation. Larvae migrate within the walls of the gastric and gastroepiploic arteries, where haemorrhagic lesions are evident from day 4 . They reach the caudal thoracic aorta via the coeliac artery approximately 10 days after hatching and remain there from days 7 to 109 where they mature to L4 (Hu and Hoeppli, 1936). After their final moult, approximately 3 months post-infection, they migrate as immature adults, from the caudal thoracic aorta to the caudal oesophagus where they are found from days 93-227. Here they live in nodules in the submucosa and adventitia of the oesophagus (Bailey, 1963). Even larvae implanted into the host sites other than the gastrointestinal tract are eventually found in the aorta or oesophagus (Bailey, 1972).

Male and female worms can be differentiated by 60 days post-infection. Mature oesophageal nodules containing adult worms are present by 3-9 months ([Bailey, 1963] and [Sen and Anataraman, 1971]). The adult is a large spiralled pink worm with males up to $54 \mathrm{~mm}$ and females up to $80 \mathrm{~mm}$ in length (Soulsby, 1982). The female worm perforates the mucosa, establishing an opening to the lumen of the oesophagus through which to pass eggs, then moves back to the submucosa or muscular layers to complete development (Bailey, 1972). A nodule eventually develops around the worm (Fig. 1). The adult worm can remain in the oesophagus for up to 2 years and the female may produce up to 3 million eggs per day (Bailey, 1972). Peak egg production appears to be between 140 and 205 days post-infection with a maximum of 2100 eggs per gram faeces (Sen and Anataraman, 1971). 


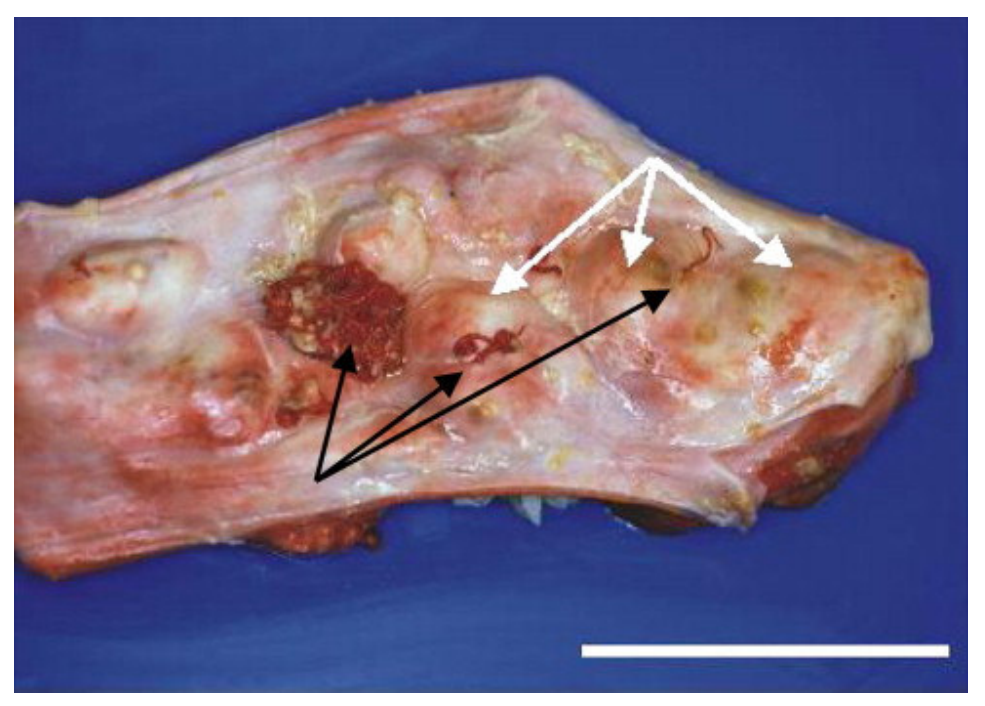

Fig. 1. The caudal oesophagus of a dog showing multiple parasitic nodules (white arrows) with red adult $S$ lupi worms (black arrows). Bar $=5.5 \mathrm{~cm}$.

Only about $47 \%$ of ingested larvae eventually establish themselves within the host (Bailey, 1972). In the initial 4 days of infection larval migration is non-directional and they may be found within the veins and lymphatics of the gastric wall. This is hypothesised to result in aberrant migration to other organs (Hu and Hoeppli, 1936). The stimulus for both directional and aberrant migration is still not known.

\section{Pathogenesis and pathology}

Larvae cause necrosis, haemorrhage and neutrophil exudation within the vessel walls in which they migrate, but, except for the thoracic aorta, these lesions usually heal completely. In the thoracic aorta, degenerate elastic and muscle tissue becomes fibrotic, and sometimes mineralised to form permanent intimal scars and aneurysms of varying size and number. These result by the sixth month post infection (Fig. 2) ([Hu and Hoeppli, 1936] and [Johnson, 1992]). Tissue damage in the aorta can be severe with 13/98 dogs in one experimental study dying 12-102 days post-infection due to aortic rupture (Bailey, 1972). The severity of damage may be associated with the amount of infective larvae taken in at a single time. Metaplastic ossification of the aorta, to the extent of bone marrow formation, has been reported (Kumar et al., 1981b). Aortic lesions are the most common lesion associated with spirocercosis and are considered pathognomonic ([Bailey, 1963] and [Ramachandran et al., 1984]). 


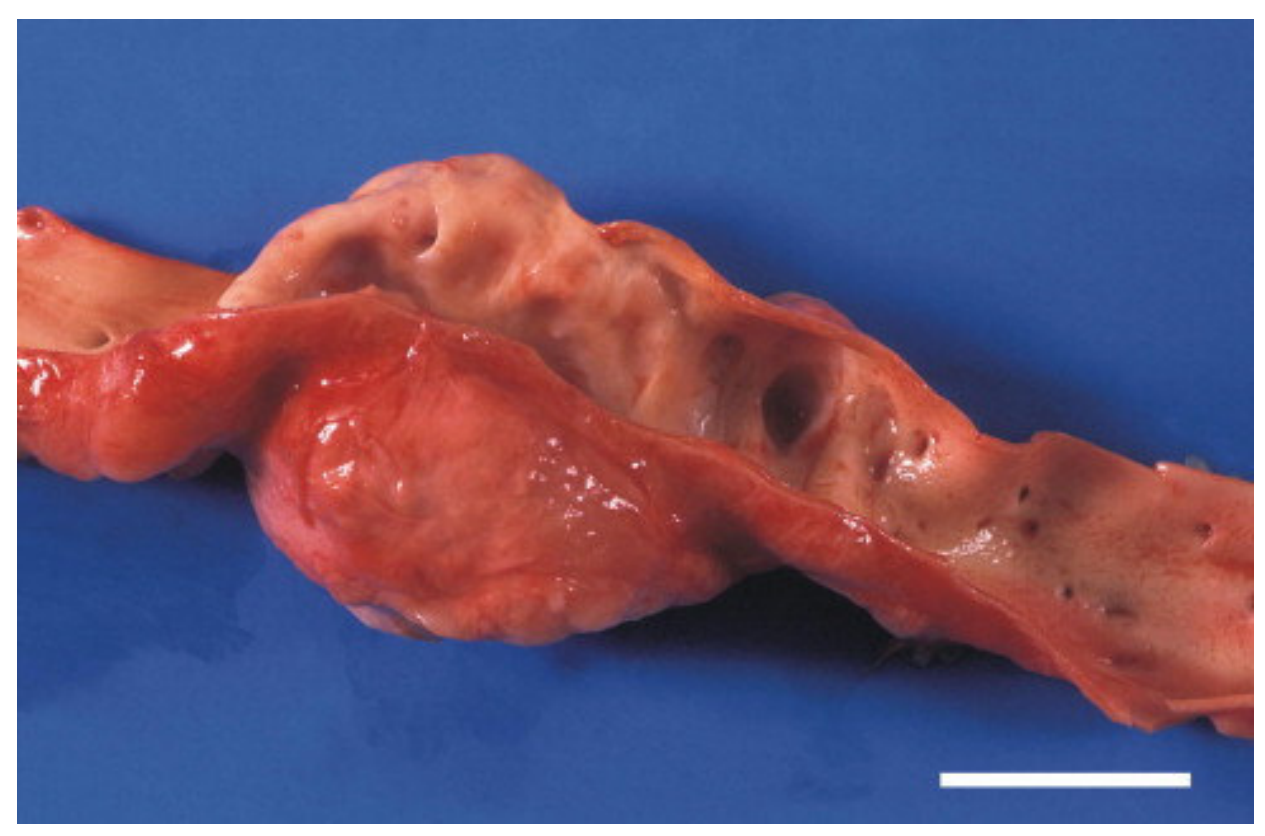

Fig. 2. The thoracic aorta of a dog with widespread $S$ lupi-associated aneurysms and mineralisation of the aortic wall. Bar $=2.5 \mathrm{~cm}$.

Spondylitis of the thoracic vertebrae is an almost invariable finding in spirocercosis but the pathogenesis has not been elucidated ([Bailey, 1963] and [Ramachandran et al., 1984]). As only the vertebrae directly adjacent to the descending aorta seem to be involved, aberrant migration or severe peri-aortic inflammation secondary to aortic migration are possible causes. Bailey (1963) recovered three worms embedded in muscle and connective tissue adjacent to the aorta and vertebral bodies in a dog with spondylitis at 90 days post-infection, supporting the theory of aberrant migration.

Usually there are one to four worm-containing nodules in the submucosa of the wall of the oesophagus, a few centimetres cranial to the diaphragm ([Bailey, 1963] and [Chandrasekharon et al., 1958]). The nodules vary from $<1$ to $>4 \mathrm{~cm}$ in diameter and not only bulge into the lumen of the oesophagus but also distort the oesophageal wall and extend into the surrounding mediastinal tissues. The number of worms present in a nodule varies from a few to $>30$, but there are typically between three and six. The nodules are usually referred to as granulomas but, histologically, this is inappropriate. Initially the worms are surrounded by highly vascularised loose connective tissue, which contains fibrin-rich fluid, neutrophils and foci of necrosis. Bailey (1963), likens it to granulation tissue. Later, this tissue is composed mostly of actively dividing fibroblasts with an embryonal appearance, sometimes resembling sarcoma (Fig. 3) ([Bailey, 1963] and [Hu and Hoeppli, 1936]). 


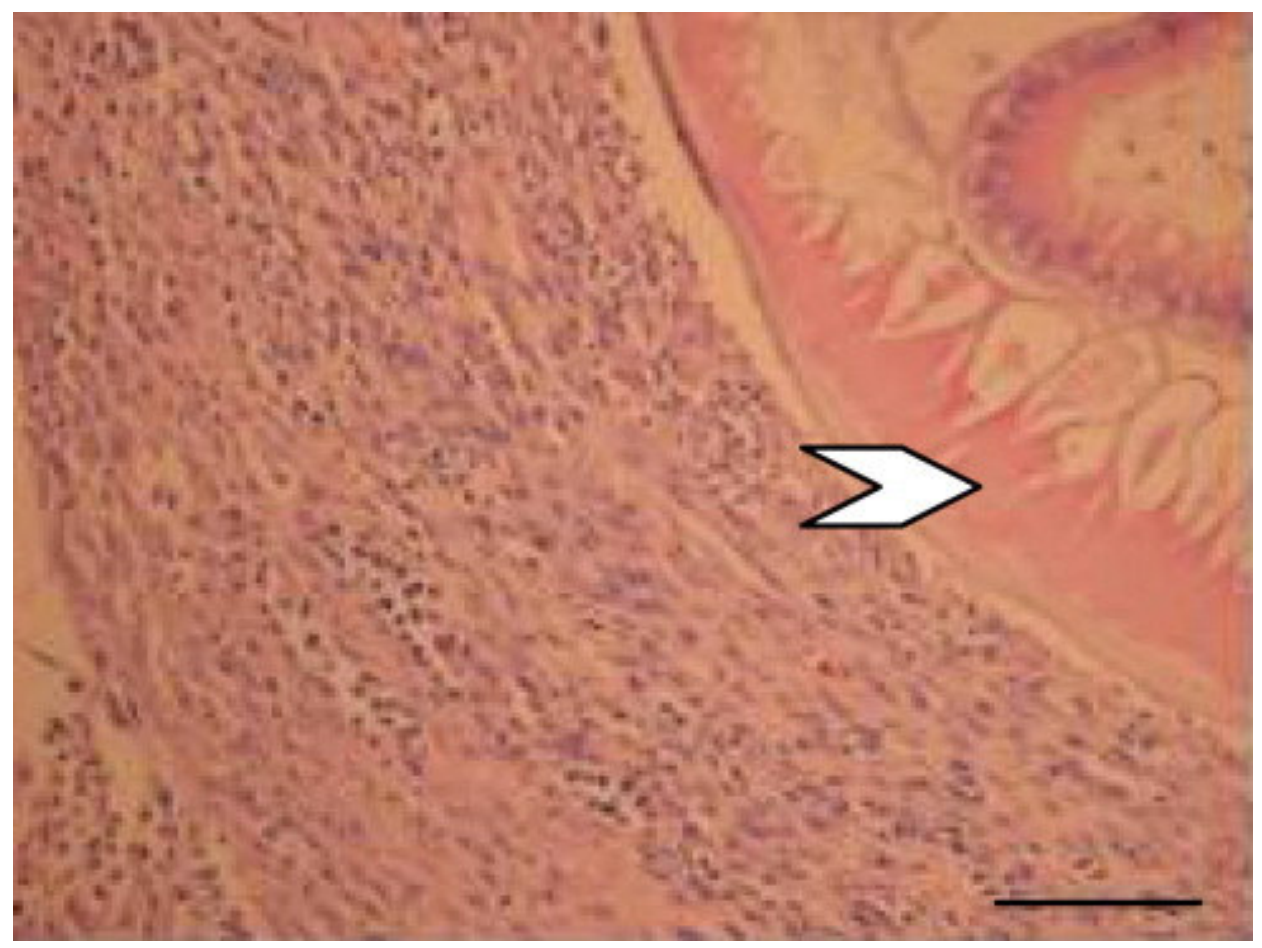

Fig. 3. Histopathological sample from an oesophageal nodule in a dog. The slide shows a segment of a cross-sectioned $S$ lupi adult (white arrow) surrounded by proliferating fibroblasts with multiple small clusters of neutrophils and plasma cells. H\&E.

Bar $=270 \mu \mathrm{m}$.

Aberrant migration of larvae is a fairly common occurrence in spirocercosis and may be responsible for the presenting clinical signs. Nodules containing worms have been found in many sites, including the stomach and intestine, mediastinum (Dvir et al., 2001), lumbar fascia (Chandrasekharon et al., 1958), rectum (Georgi et al., 1980), trachea, interdigital tissue (Bailey, 1963), lung (Stephens et al., 1983), thymus (Rajan and Mohiyuddeen, 1974), diaphragm (Harrus et al., 1996), heart (Garg et al., 1989), kidney, subcutis (Singh et al., 1999) and urinary bladder (Thanikachalam et al., 1984). Some experimentally infected dogs have demonstrated spontaneous regression of oesophageal nodules even though pathognomonic aortic lesions were present (Bailey, 1972).

\section{Neoplastic transformation}

The association between spirocercosis and neoplasia was first reported by Seibold et al. (1955), with numerous subsequent reports in the literature ([Bailey, 1963] and [Bailey, 1972]). Chronic helminthiasis is recognised as a significant factor in cancer development in humans (Herrera and Ostrosky-Wegman, 2001). Oesophageal tumours are rare in dogs and account for only $0.5 \%$ of canine neoplasms (Ridgway and Suter, 1979). Bailey (1963) summarised 39 cases diagnosed with oesophageal sarcoma. These cases were extracted from a total of 3148 necropsies. Although only $8 \%$ of all the dogs necropsied were infected with $S$. lupi, there was direct or very strong presumptive evidence of $S$. lupi 
infection in 38/39 dogs diagnosed with oesophageal sarcoma: 15/39 cases had adult $S$. lupi in or around the oesophageal masses, 32/39 cases had characteristic lesions in the aorta and 26/39 cases had spondylitis, indicating prior infection with $S$. lupi. The oesophageal masses were typically cauliflower like, irregular and pedunculated with a variable amount of superficial necrosis and originated in the portion of the oesophagus where S. lupi induced lesions are typically found (Fig. 4). Histopathologically, ossification was found in 26/39 neoplasms. These neoplasms are true malignancies since metastasis, particularly to the lungs, is frequently noted (Bailey, 1963). Osteosarcoma appears to occur more commonly than fibrosarcoma, being present in approximately in $60 \%$ of cases (Bailey, 1963).

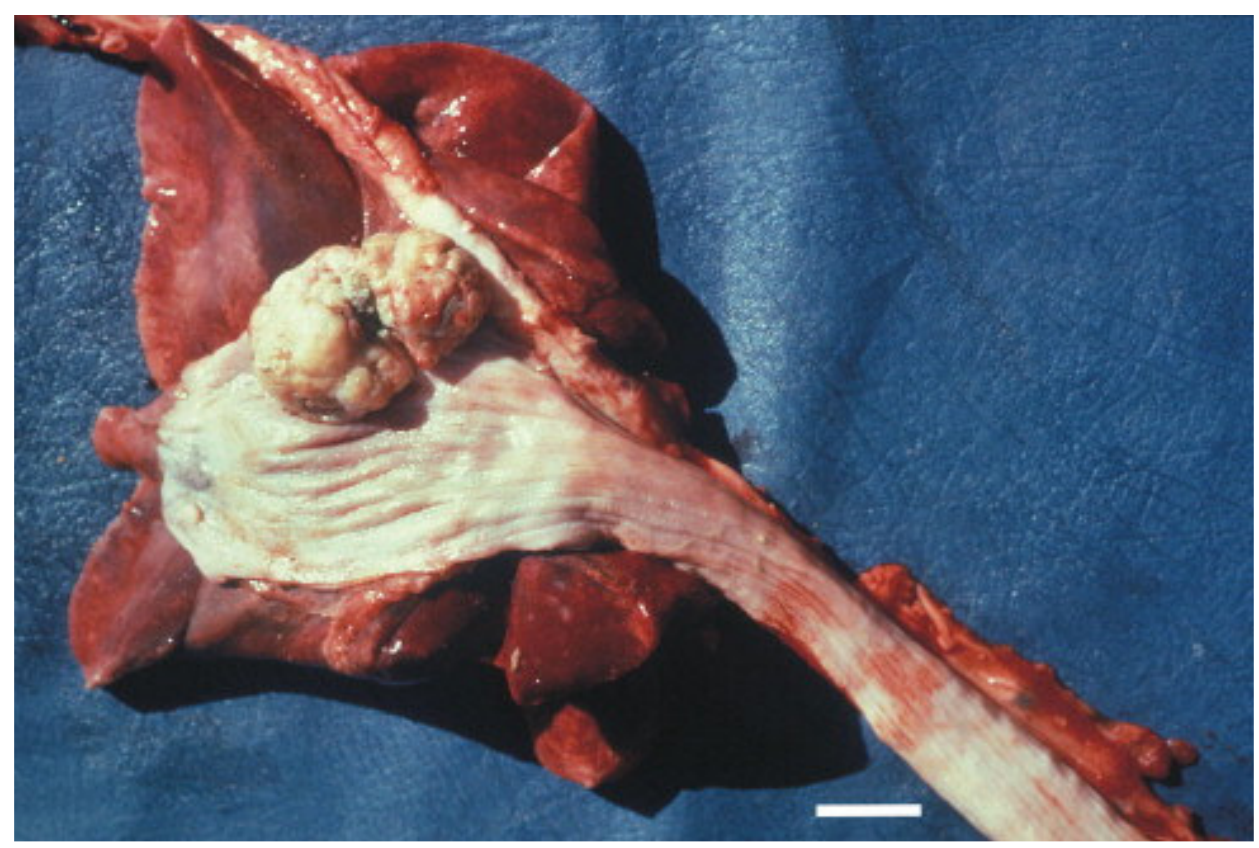

Fig. 4. Caudal oesophagus of a dog showing a cauliflower-like mass which is a $S$ lupiassociated osteosarcoma with regional megaoesophagus. Bar $=5 \mathrm{~cm}$.

In a report from Kenya, 42/206 spirocercosis cases had sarcomas, with 17/42 being fibrosarcomas and 25/42 osteosarcomas. Twenty-four of these cases (57\%) had worms contained within the sarcomatous tissue (Wandera, 1976). A distinct age predisposition was also noted in this study with dogs younger than 2 years of age having oesophageal fibrosarcoma and those older than 5 years having osteosarcoma. In a more recent report of 15 cases, nine were diagnosed with osteosarcoma, five with fibrosarcoma and one with an undifferentiated sarcoma (Ranen et al., 2004). The vast majority of cases showing neoplastic transformation have occurred in the typical caudal oesophageal region. Three non-oesophageal $S$. lupi associated sarcomas have been reported and involved the aorta, lung and vertebra ([Bailey, 1963], [Stephens et al., 1983] and [Wandera, 1976]).

A murine xenograft model of spirocerca-associated sarcoma has been established (Stettner et al., 2005). In this study, three tumours lines were established: a typical 
fibrosarcoma, a moderately aggressive osteosarcoma and a relatively non-aggressive osteosarcoma. This diversity in tumour lines is advantageous as their diverse behaviour patterns mimic the natural situation. This allows comparison between different tumour types, degrees of malignancy and growth rates in dogs.

\section{Clinical signs}

The clinical signs of spirocercosis vary greatly, depending on the stage of disease, aberrant migrations and possible complications. Early migration of larvae through the gastric mucosa is associated with acute onset vomition in experimental cases ([Bailey, 1972] and [Hu and Hoeppli, 1936]). An uncomplicated infection may be sub-clinical, or show vomiting or regurgitation, weight loss and dysphagia due to the development of a caudal oesophageal mass (Mazaki-Tovi et al., 2002). The dog may also breathe shallowly and sit with its head extended (Evans, 1983). A few studies characterise the clinical signs exhibited by patients affected with $S$. lupi. The data are summarised in Table 1 .

Table 1.

Clinical and clinicopathological signs associated with $S$. lupi infection

\begin{tabular}{|c|c|c|c|}
\hline \multicolumn{4}{|l|}{ Clinical signs } \\
\hline & Mazaki-Tovi $(n=50)$ & Dvir $(n=27)$ & Ranen $(n=17)$ \\
\hline Gastrointestinal & $n=33(66 \%)$ & $n=8(30 \%)$ & $n=16(94 \%)$ \\
\hline Vomition + regurgitation & 30 & 7 & 16 \\
\hline Melaena & 9 & 1 & 5 \\
\hline Hypersalivation & 4 & 5 & 4 \\
\hline Diarrhoea & 4 & & \\
\hline Dysphagia & & 4 & \\
\hline Submandibular salivary gland enlargement & & & 5 \\
\hline Haematemesis & & & 3 \\
\hline Respiratory & $n=10(20 \%)$ & $n=16(59 \%)$ & $n=3(18 \%)$ \\
\hline Dyspnoea & 6 & 11 & \\
\hline Coughing/retching & 5 & 7 & 3 \\
\hline Abnormal respiratory sounds & & 2 & \\
\hline Neurological & $n=7(14 \%)$ & $n=3(11 \%)$ & \\
\hline Paraparesis & 7 & & \\
\hline
\end{tabular}




\begin{tabular}{|c|c|c|c|}
\hline \multicolumn{4}{|l|}{ Clinical signs } \\
\hline & Mazaki-Tovi $(n=50)$ & Dvir $(n=27)$ & Ranen $(n=17)$ \\
\hline Seizures & & 3 & \\
\hline Musculoskeletal & $n=2(4 \%)$ & $n=8(30 \%)$ & $n=10(59 \%)$ \\
\hline Back pain & 2 & & \\
\hline Lameness & & 6 & \\
\hline Weakness/lethargy & & 3 & 10 \\
\hline \multicolumn{4}{|l|}{ Other } \\
\hline Pyrexia & 12 & 14 & 7 \\
\hline Weakness & 11 & 1 & \\
\hline Anorexia & 9 & 18 & 7 \\
\hline Weight loss & 5 & 20 & 6 \\
\hline Generalised lymphadenopathy & & 8 & \\
\hline Acute death & & 2 & \\
\hline Muffled heart sounds & & 1 & \\
\hline No clinical signs & 2 & & \\
\hline Clinical pathology & $n=47(95 \%)$ & & $n=14(82 \%)$ \\
\hline Anaemia & 25 & & 8 \\
\hline Leukocytosis & 15 & & 14 \\
\hline
\end{tabular}

A composite of three separate studies ([Dvir et al., 2001], [Mazaki-Tovi et al., 2002] and [Ranen et al., 2004]). It must be noted that the cases in the Ranen study were all diagnosed with oesophageal sarcoma whereas those in the first two studies were more typical spirocerca cases.

Complicated cases may result from normal or aberrant nematode migration. The normal migration route along the gastro-aortic arterial system may result in either rupture of the aorta, causing haemothorax and acute death, or other major blood vessels, resulting in the development of large haematomas ([Bailey, 1963], [Dvir et al., 2001] and [Hamir, 1984]). Migration through the aortic wall to the oesophagus is via the mediastinum and 
may result in mediastinitis, pneumomediastinum, pleuritis or pyothorax which will present clinically as dyspnoea of varying magnitudes ([Dvir et al., 2001] and [Hamir, 1986]). Some patients may develop aspiration pneumonia secondary to the oesophageal lesion.

Sialoadenosis has been associated with $S$. lupi nodules and results in moderate to severe dysphagia (Schroeder and Berry, 1998). Metastases to the lungs secondary to neoplastic transformation of the nodule may contribute to the dyspnoea. Patients with oesophageal sarcomas have also shown a strong tendency to develop hypertrophic osteopathy with subsequent lameness (Brodey et al., 1977). Concurrent bacterial infection may lead to discospondylitis ([Bailey, 1963] and [Fox et al., 1988]), septic polyarthritis (Dvir et al., 2001), endocarditis and interstitial nephritis (Harrus et al., 1996). Non-specific clinical signs associated with $S$. lupi are pyrexia, occurring in $>50 \%$ cases, and mild peripheral lymphadenopathy ([Dvir et al., 2001] and [Mazaki-Tovi et al., 2002]). Aberrant migration may result in any form of clinical disease, but the most common presentations include respiratory, neurological and musculoskeletal signs (Dvir et al., 2001).

At our hospital, signs other than regurgitation, which raise a suspicion of $S$. lupi, are dyspnoea; often only a subtle tucking in of the abdomen and flaring of the ribcage, and dysphagia; ranging from mild to severe, often associated with enlarged mandibular salivary glands and hypersalivation.

Additional reported complications of spirocercosis include aortic thromboembolism ([Alvarenga and Saliba, 1971], [Gal et al., 2005] and [Wandera, 1976]), aberrant migration to the vertebral canal ([Smith and Knottenbelt, 1989], [Tudury et al., 1995] and [du Plessis et al., in press]), secondary megaoesophagus ([Dvir et al., 2001] and [Londono et al., 2003]), haemopericardium (Pereira et al., 1995), oesophageal obstruction or perforation ([Chandrasekharon et al., 1958], [Hamir, 1986] and [Klainbart et al., in press]) and gastro-oesophageal intussusception (Rallis et al., 1995).

\section{Diagnosis}

\section{Faecal flotation}

The female worm produces numerous small $(35 \times 15 \mu \mathrm{m})$ thick shelled larvated eggs (Fig. 5). Several factors affect the results of faecal flotation. Passage of eggs occurs for a relatively short period in the lifespan of the worm and is thus unpredictable. Eggs will only be present in the faeces when the female has a patent passage to the oesophageal lumen thus maturation of the nodule is essential. Eggs are difficult to detect in direct faecal preparations and routine flotation techniques using sugar and salt solutions thus requiring special laboratory techniques (Fox et al., 1988). The modified Stoll technique, is purported to make the solution clearer and facilitates visualisation of the eggs (Cabrera and Bailey, 1964). Flotation with sodium nitrate solution with an SG of 1.36 or supersaturated $33 \%$ zinc sulphate will concentrate the eggs. Improved diagnostic sensitivity has been shown with a modified sugar flotation technique (Markovics and Medinski, 1996). It is important to repeat a negative faecal flotation to improve diagnostic accuracy. The sensitivity of faecal flotation in the study by Mazaki-Tovi et al. 
(2002) was $80 \%(n=40)$, with $72 \%$ of the positives detected on the first examination and the remainder on a second examination performed a few days later.

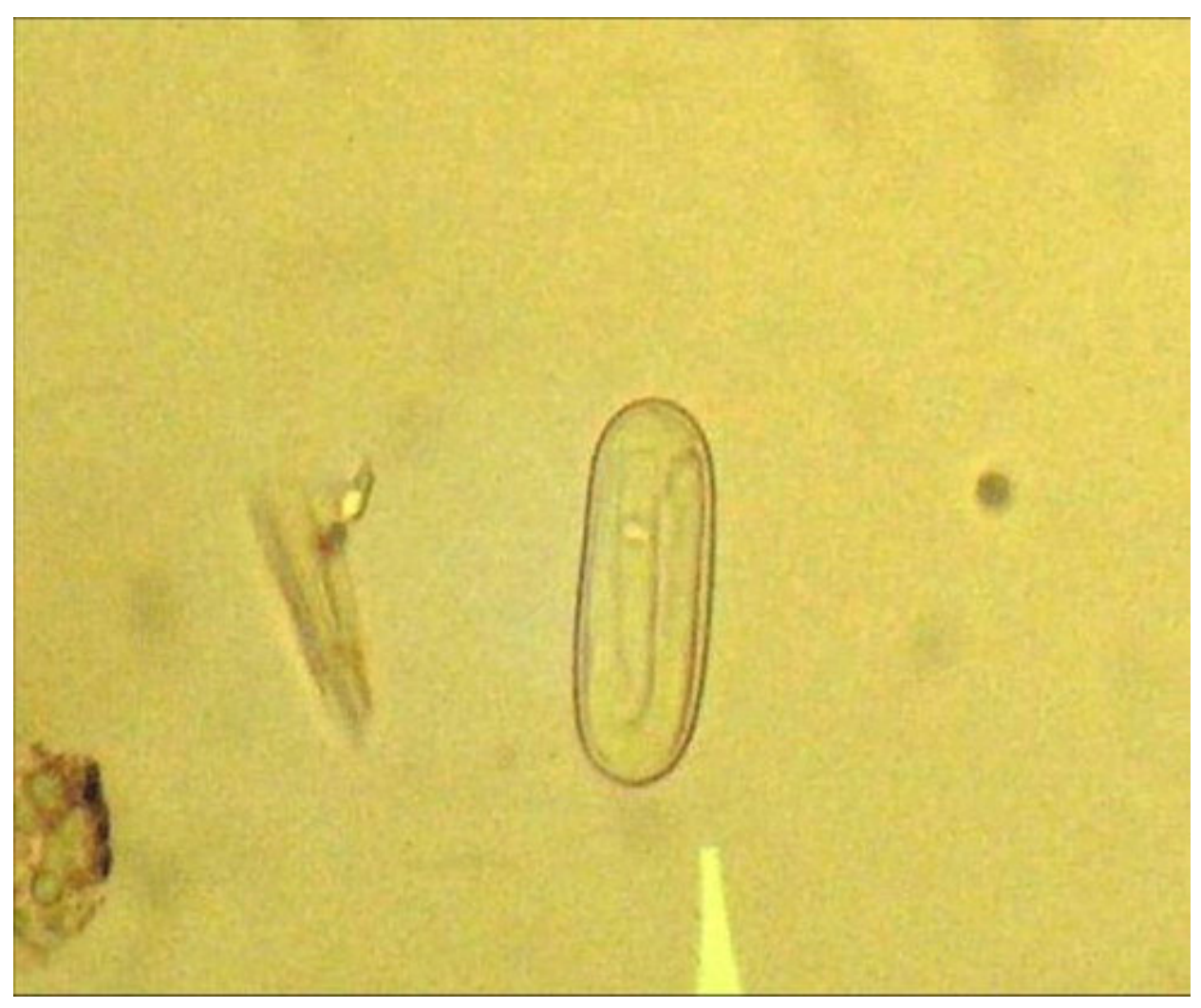

Fig. 5. A thick-shelled larvated $S$ lupi egg $35 \times 15 \mu \mathrm{m}$. To allow for comparative sizing: Ancylostoma caninum eggs are usually $56-65 \mu \mathrm{m}$ in length.

\section{Clinical pathology}

Mild anaemia is well described and is present in approximately $50 \%$ of cases ([MazakiTovi et al., 2002] and [Ranen et al., 2004]). Patients whose nodules have transformed into sarcomas showed an increased incidence of microcytic hypochromic anaemia, which was ascribed to chronic blood loss and melaena due to ulceration of the oesophageal mass (Ranen et al., 2004). Patients with early disease were likely to present with normocytic normochromic anaemia (Mazaki-Tovi et al., 2002). Animals presented with advanced disease were also more likely to show leukocytosis. In one study of oesophageal osteosarcomas, $82 \%$ of cases presented with a leukocytosis, compared to only $32 \%$ of patients with earlier disease ([Mazaki-Tovi et al., 2002] and [Ranen et al., 2004]). Monocytosis was also common, whereas eosinophilia was uncommon (Mazaki-Tovi et al., 2002). There was no correlation between the white cell counts and the existence of any associated inflammatory conditions such as pneumonia or spondylitis and it thus appears that the inflammatory response is as a result of the granuloma itself (MazakiTovi et al., 2002). 
There are no typical reported biochemical changes in dogs with early disease other than a mildly elevated creatine kinase in 54\% of dogs in the Mazaki-Tovi et al. (2002) study. Once neoplastic transformation has occurred, however, increased alkaline phosphatase, creatine kinase, amylase and lactate dehydrogenase have been noted (Ranen et al., 2004). Brodey et al. (1977) reported no blood chemistry or haematological differences between native dogs in Kenya with or without spirocercosis.

\section{Serology}

An IFA test using the mid-body region of the male worm as an antigen source that was $100 \%$ sensitive and $80 \%$ specific for $S$. lupi at a titre of 1:640 has been described (Coskun, 1995). Nothing further has been published in this potentially useful diagnostic field.

\section{Diagnostic imaging}

Radiography plays an essential role in the diagnosis of spirocercosis and is often the initial diagnostic modality. Computed tomography (CT) has recently also been shown to be valuable in diagnosing small lesions or for treatment planning (Dvir et al., 2001). In evaluating radiographic or CT images the changes may be classified as primary or secondary (distant).

In clinically affected patients, the typical oesophageal mass will usually be seen on radiographs. In the majority of patients the mass is found in the caudal oesophagus (Dvir et al., 2001). A moderate amount of air may be present cranial to the mass. The mass is best seen on a ventrodorsal (VD) or dorsoventral (DV) view as a single midline soft tissue opacity superimposing on the caudal cardiac border and diaphragmatic cupula (Fig. 6). The left border of the descending aorta is normally a straight edge converging to the midline in the region of the cranial extent of the diaphragm. In affected dogs this line may become undulant due to aneurysm formation (Fig. 6). These changes are also occasionally seen in the ascending aorta on lateral views. 


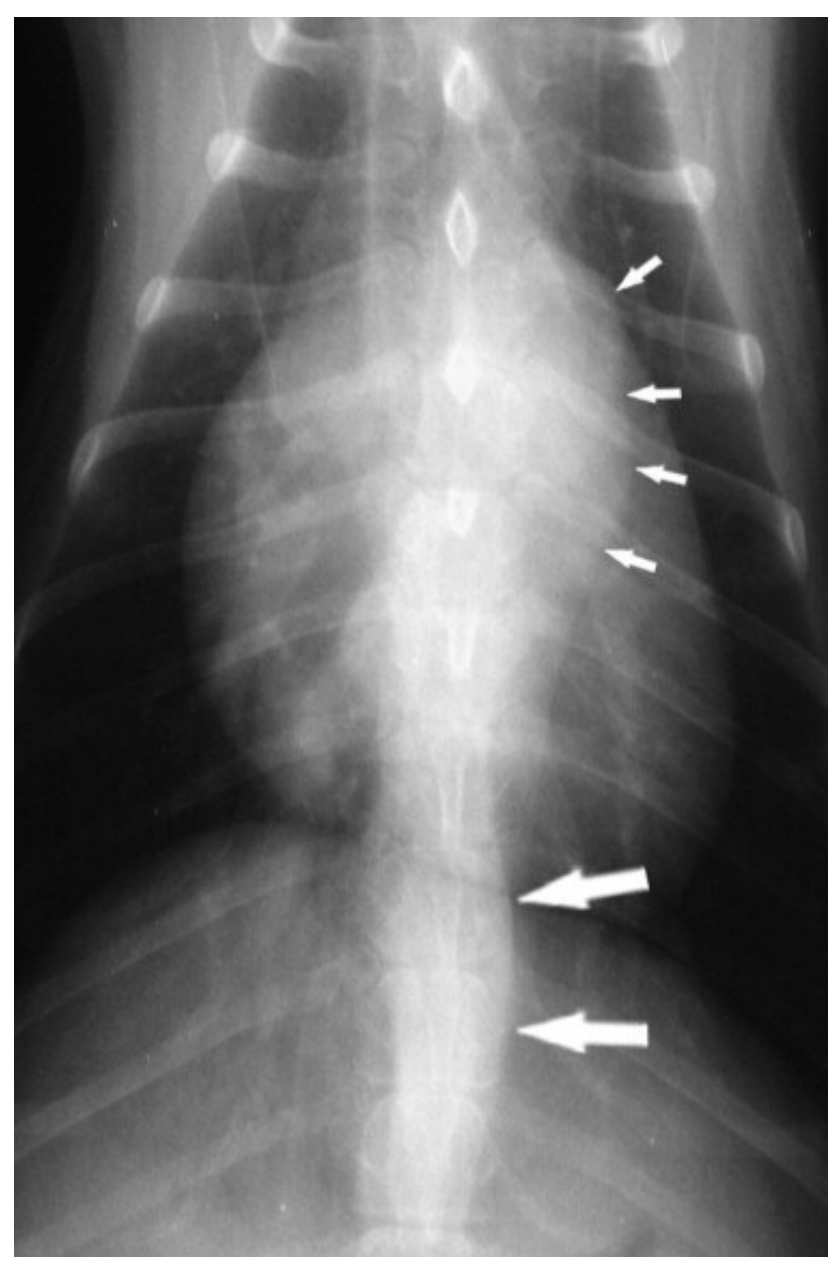

Fig. 6. Dorsoventral thoracic radiograph of a dog. The short arrows indicate the irregular outline of the left lateral border of the initial descending aorta, indicative of multiple aortic aneurysms. The large arrows indicate a typical small caudal oesophageal mass due to $S$. lupi.

Dogs presented with a history of vomiting and undergoing abdominal radiography must also have this region evaluated on the cranial periphery of the VD abdominal radiograph. Unless large, the mass is often poorly seen on lateral views where it is located dorsally to the caudal vena cava (two showed mineralisation of the mass on radiographs.

Fig. 7). A right lateral recumbent view is preferable as the normal oesophagus is usually not seen on this view, whereas in large breed dogs a normal oesophagus may be seen on left lateral recumbent radiographs which could be mistaken for an oesophageal mass (Avner and Kirberger, 2005). The mass may be up to $165 \mathrm{~mm}$ long and $100 \mathrm{~mm}$ high and its centre point is likely to be caudal to the eighth thoracic vertebra. The mass may contain mineralised opacities which could be ingested bone debris trapped in the irregular surface of the mass or neoplastic transformation to an osteosarcoma. Mass mineralisation is a radiographic marker for neoplastic transformation. Of the $10 \mathrm{dogs}$ with neoplasia in the study by Dvir et al. (2001), 


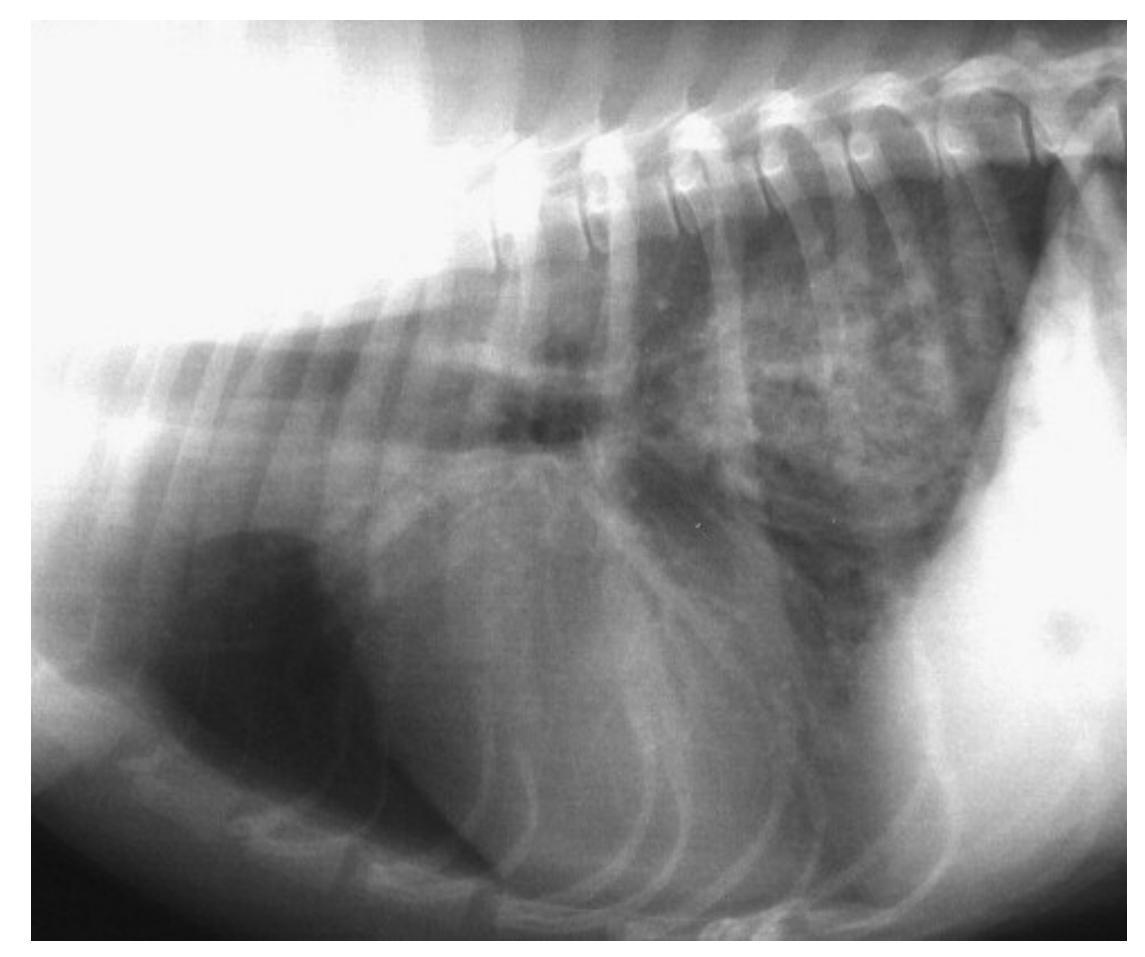

Fig. 7. Right lateral thoracic radiograph of a dog with a large poorly defined soft tissue opacity, an advanced $S$. lupi mass between the caudal vena cava and caudal thoracic aorta. See also Fig. 10.

On the lateral thoracic radiograph the ventral borders of the caudal thoracic vertebra should be examined for evidence of spondylitis. The ventral vertebral border is usually concave but with presumed aberrant larval migration, a secondary inflammatory reaction can take place on the vertebral body resulting in a lamellar, thick brush-like or solid periosteal reaction filling up the ventral surface of the vertebral body, giving it a rectangular or even bulging appearance (Fig. 8). Spondylitis may be seen in up to $25 \%$ of affected dogs and affects one to six vertebrae dorsal to the caudal oesophagus (T5 - T12). Occasionally the disc space is bridged giving the appearance of spondylosis. Spondylitis should not be confused with the common radiological finding of spondylosis, which is a non-inflammatory osseous bridging of the intervertebral disc space. Aortic mineralisation secondary to small aneurysms is occasionally seen on the lateral view ([Dvir et al., 2001] and [Mazaki-Tovi et al., 2002]). This is seen as one or two 5-10 mm long mineralised streaks in the aortic intima and is thus seen on the dorsal or ventral edge of the thoracic aorta. 


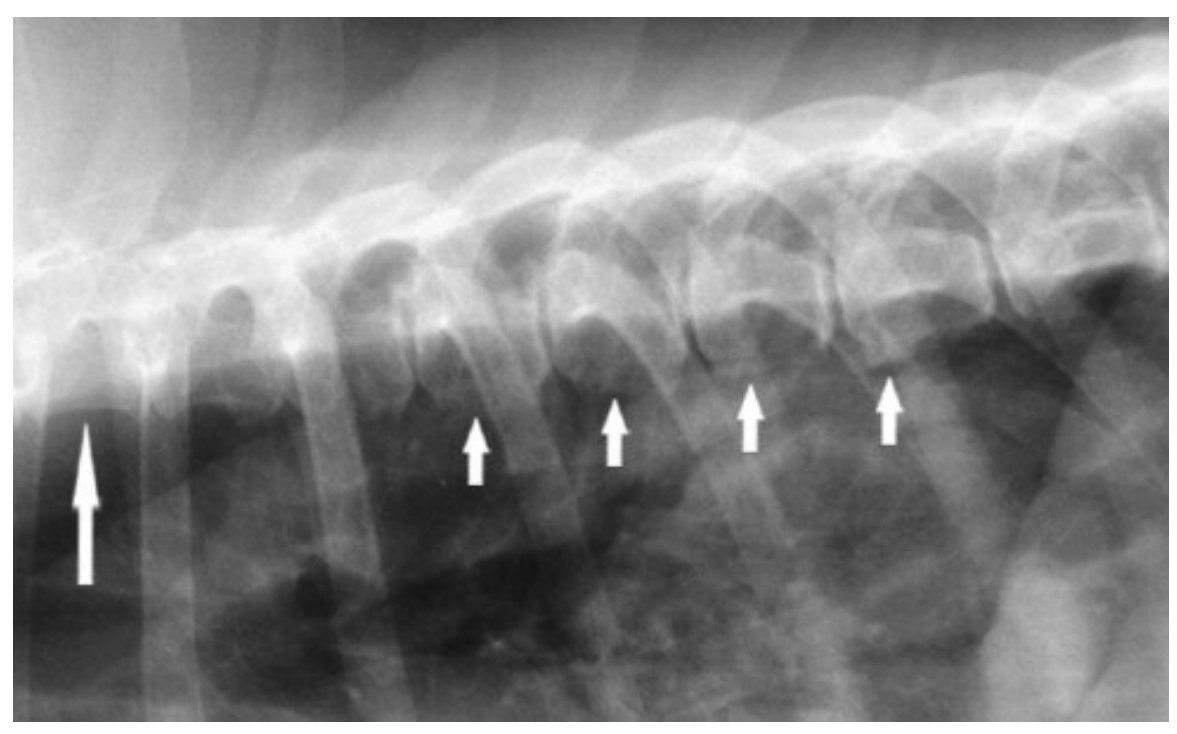

Fig. 8. Close-up lateral view of caudal thoracic vertebrae with short arrows illustrating varying degrees of ventral spondylitis. Compare these to the cranial vertebra (long arrow) with its normal ventrally concave vertebral body.

Small oesophageal nodules or more cranially located oesophageal pathology (centre point ventral to T6) are difficult to see radiologically due to superimposition of other hilar structures. Cranially located masses are generally about $70 \%$ smaller than typical caudal oesophageal masses (Dvir et al., 2001). No radiological masses were observed in 7-14\% of cases ([Dvir et al., 2001] and [Mazaki-Tovi et al., 2002]). Barium sulphate may be administered and the nodule will usually be seen as a dorsal oesophageal mural filling defect (Fig. 9). An alternative technique is pneumo-oesophagography. Under general anaesthesia an endotracheal tube is placed in the oesophagus, and the latter is inflated and the tube sealed off with a stopper. Lateral, and if required DV/VD, thoracic radiographs are immediately made. This often results in excellent visibility of the nodule(s) due to the contrasting gas in the oesophagus and the surrounding lungs (Fig. 10). 


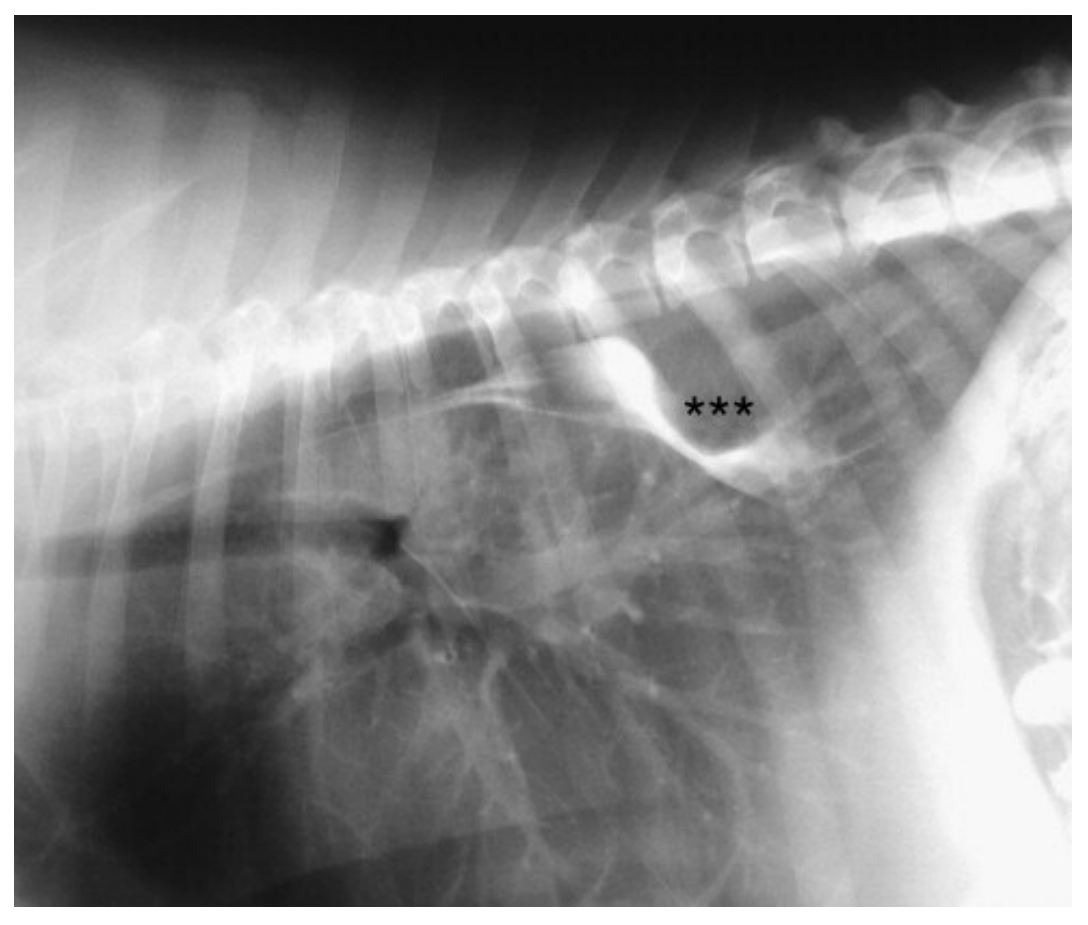

Fig. 9. Positive contrast oesophagogram illustrating a round dorsal mural filling defect (***) due to a $S$. lupi granuloma. The whole oesophagus has been displaced dorsally by a mass in the region of the tracheobronchial lymph nodes, which, on post-mortem, was an abscess secondary to $S$. lupi induced mediastinitis.

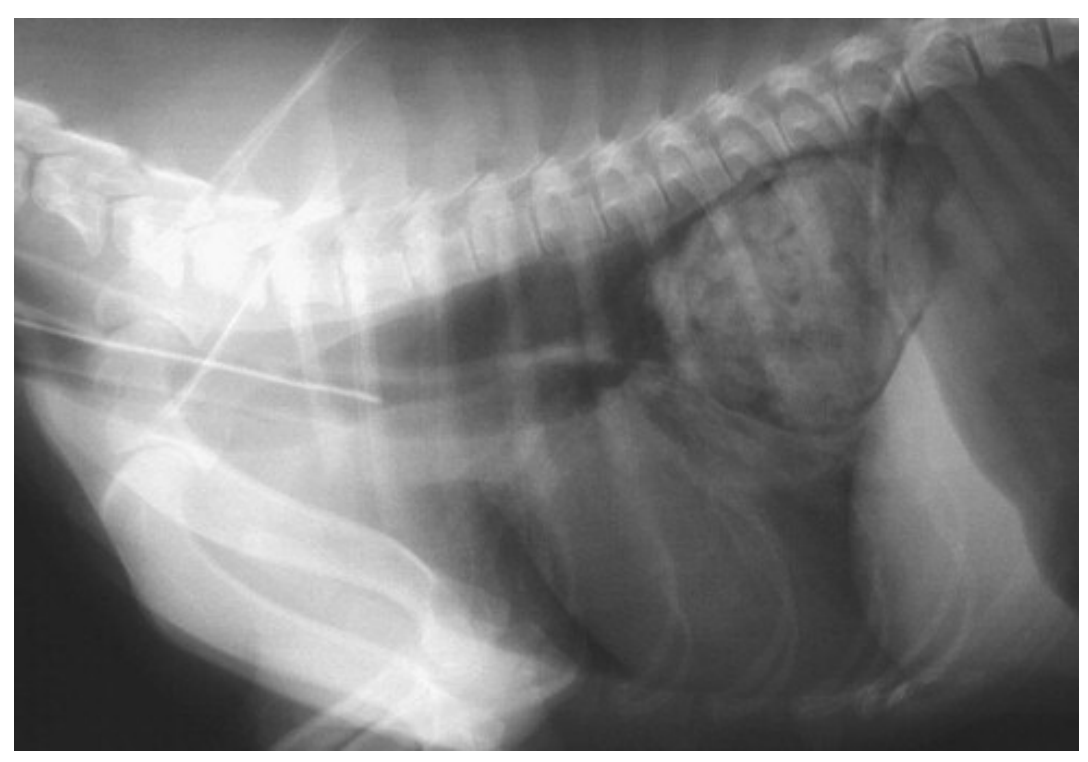

Fig. 10. Right lateral thoracic view with pneumo-oesophagogram of the same dog as in Fig. 7. Note the endotracheal tubes in the trachea and oesophagus. The oesophagus is air 
filled with a prominent tracheo-oesophageal stripe sign and the caudal oesophageal mass is much better defined than in Fig. 7.

Disease complications (secondary changes) detected on radiographs include tracheal or bronchial displacement or compression (Fig. 9), pleural effusion, pulmonary metastases, alveolar or interstitial lung patterns, mediastinitis, pneumothorax, mineralisation of the mass, pneumomediastinum and hypertrophic osteopathy (Dvir et al., 2001).

Computed tomography provides cross sectional slices of the thorax and images can also be reformatted into other planes. After image acquisition images can be viewed in soft tissue, bone or air windows allowing different aspects of the disease to be evaluated. In our hospital, CT is used for surgical planning, prognostication and where pleural or mediastinal fluid effaces structures on the radiograph. Adding air to the oesophagus prior to scanning is useful to better delineate the oesophageal mass. Soft tissue windows allow for evaluating the extent of the lesion, identifying pleural, mediastinal and pulmonary pathology, and assessing lesion and aortic mineralisation (Fig. 11). Bone windows allow better evaluation of spondylitis and lung windows allow for detection of pulmonary changes not seen on radiographs such as pulmonary metastases. Intravenous contrast medium administration may assist in delineating pathology in certain cases and is particularly useful for detecting thrombosis associated with thoracic aortic aneurysms. Computed tomography has been shown to be remarkably more accurate than thoracic radiography in detecting small pulmonary nodules as well as assessing the total number and location of nodules (Nemanic et al., 2006). 


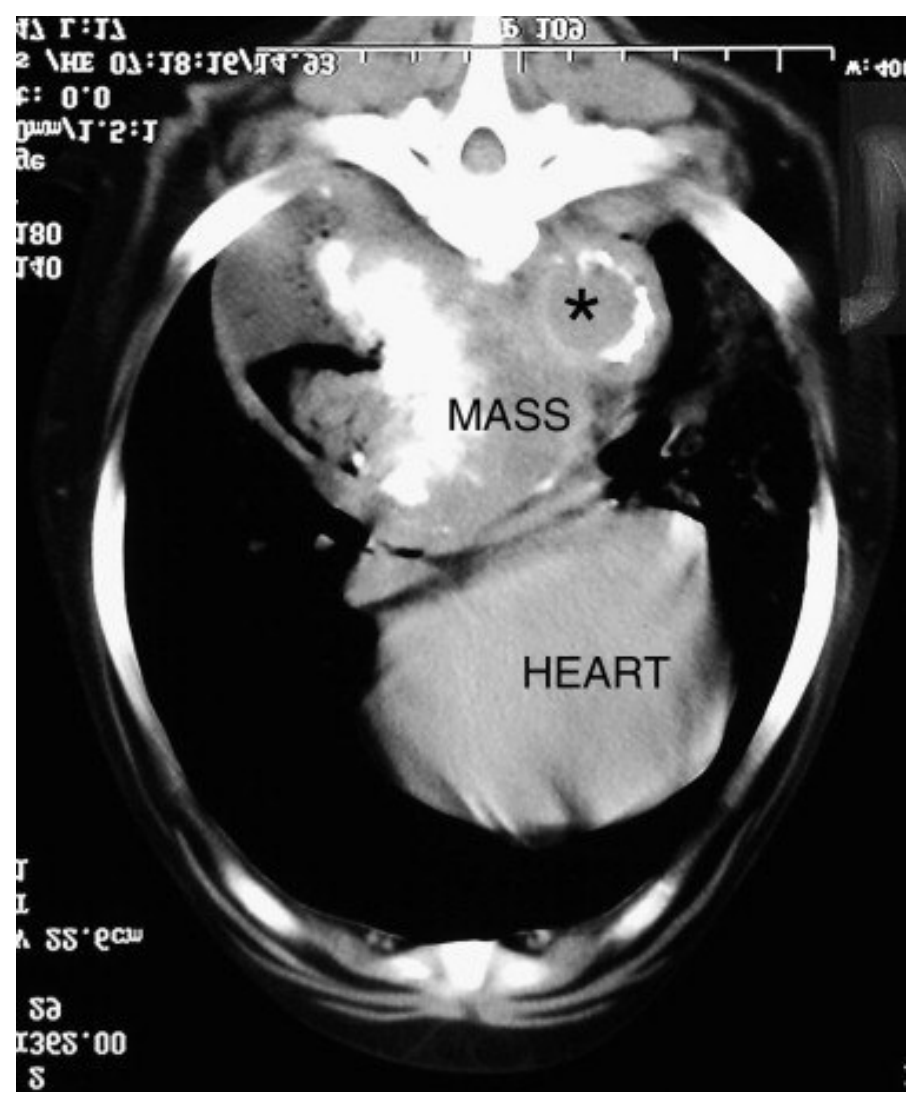

Fig. 11. Transverse thoracic computed tomography image utilising a soft tissue window. The $S$. lupi-associated mass is located dorsal to the heart and shows marked central mineralisation and invasion of the air filled oesophagus. The aorta $(*)$ shows advanced mineralisation of its lateral wall.

Diagnostic ultrasonography via a trans-hepatic window to avoid the aerated lungs is currently being investigated in our hospital. Oesophageal masses adjacent to the diaphragm can be seen (Fig. 12) and we have taken trans-hepatic ultrasound-guided biopsies of large masses for histopathology. 


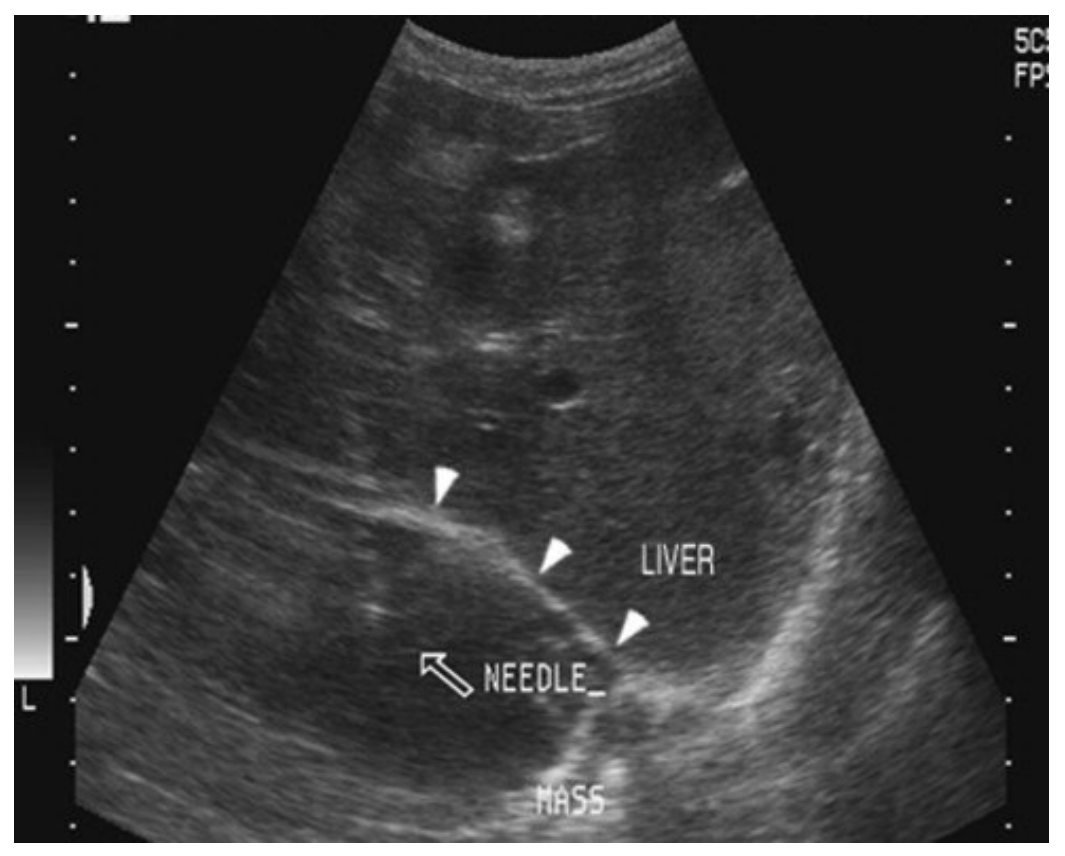

Fig. 12. Transverse trans-hepatic ultrasonographic image of a hypoechoic $S$. lupi mass beyond the hyperechoic diaphragm line (arrows). The open arrow points toward the trans-hepatic echogenic biopsy needle outline.

\section{Oesophagoscopy}

Endoscopy is more sensitive than radiography in diagnosing a $S$. lupi infection, which has only progressed to small nodule formation within the oesophagus. Mazaki-Tovi et al. (2002) showed a $100 \%$ sensitivity of endoscopy compared to a $80 \%$ sensitivity of faecal flotation and $53 \%$ sensitivity of radiographs in diagnosing an oesophageal mass. The sensitivity of radiographic diagnosis was increased to $86 \%$ when the presence of spondylitis, present in $33 \%$ of cases, was also considered a positive diagnosis.

Endoscopic findings vary depending on the progression of the disease. Early infection typically presents with one or several smooth rounded nodules, which may have a pink nipple-like protuberance through which the female worm may be seen protruding as she lays eggs (Fig. 13). These nodules are typically found caudal to the heart and may extend through the cardia into the stomach (Kumar et al., 1981a). Gastric nodules were found on necropsy in 5\% of dogs reported on from Iraq and 3\% in Kenya (Brodey et al., 1977). It is important to inflate the oesophagus adequately to avoid mistaking smaller nodules for oesophageal folds. 


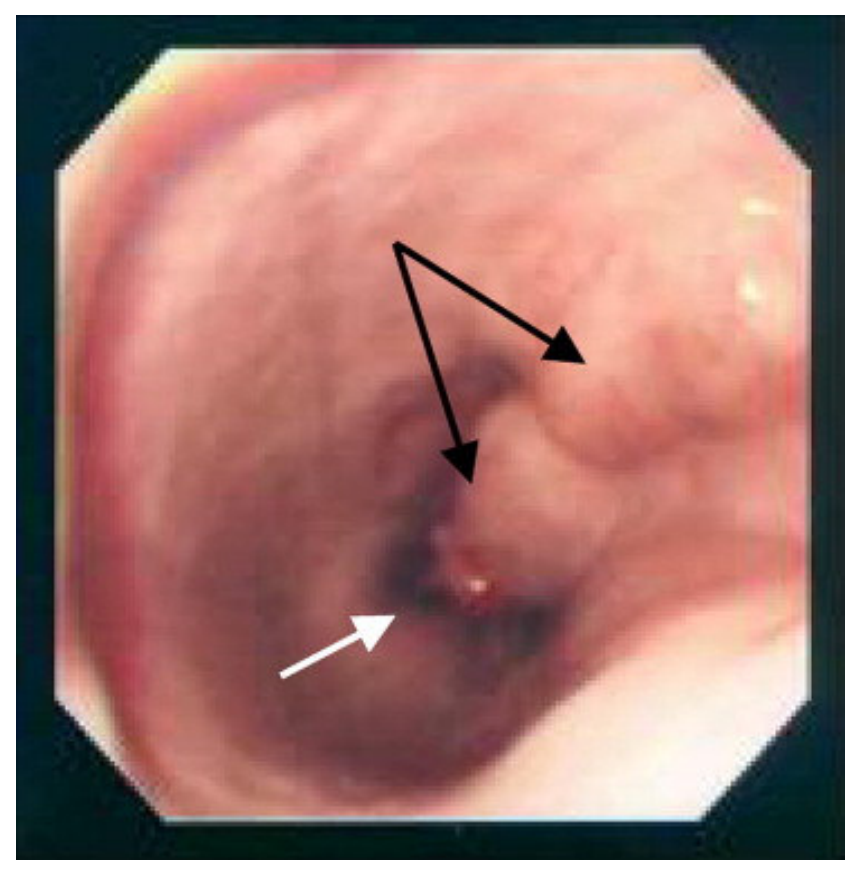

Fig. 13. Oesophageal endoscopy in a dog showing the appearance of the oesophagus in a typical case of spirocercosis. Two coalescing nodules (black arrow) are present. Note the pink tip of the nodule through which the female lays eggs (white arrow). Note also that the oesophagus is distended with air to facilitate visualisation of the nodules.

Over time, nodules may enlarge and become roughened, lobulated, frequently pedunculated, cauliflower-like masses, which obliterate the oesophageal lumen (Fig. 14). These masses are often necrotic and may be ulcerated and friable, bleeding easily if traumatised by the endoscope. It is our experience that once the masses have this macroscopic appearance, that they may have already undergone neoplastic transformation. It is often difficult to determine the extent of the mass, involvement of gastro-oesophageal sphincter and type of attachment to oesophageal wall of these nodules endoscopically as the mass physically hampers complete visualisation. Some masses are extraluminal (intramural or mediastinal) and the only abnormality visualised is a narrowed oesophagus (Dvir et al., 2001). Additional oesophageal pathology such as oesophagitis may also be diagnosed. 


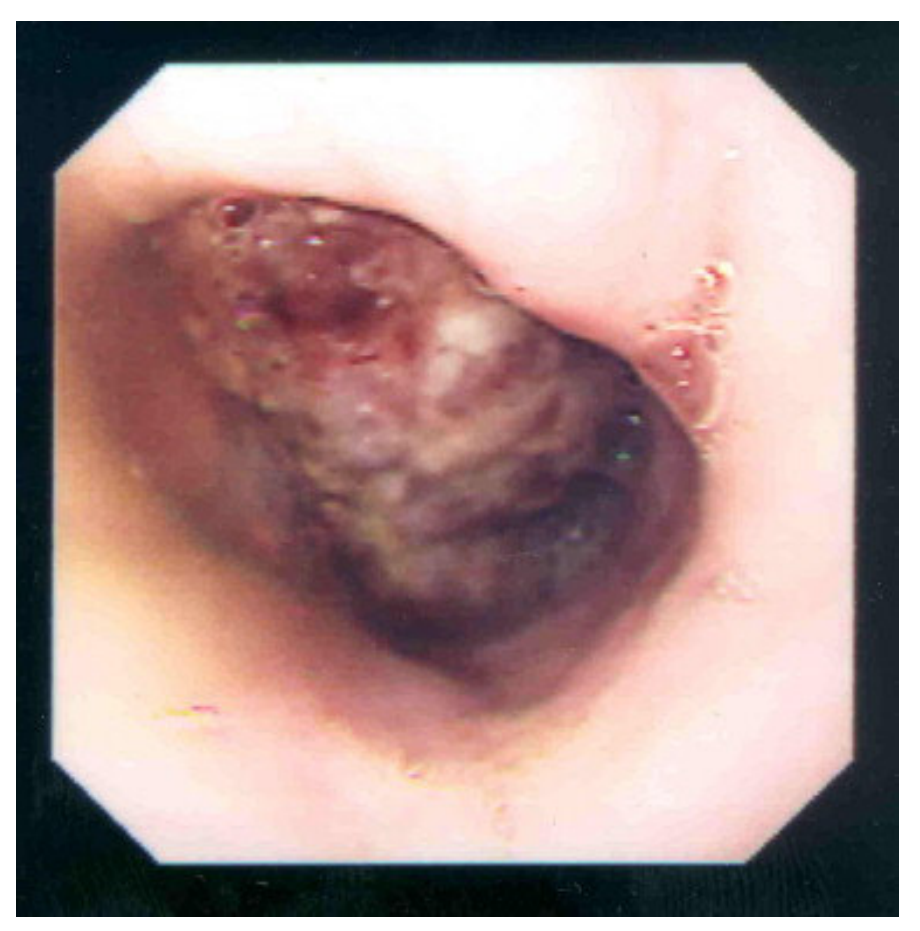

Fig. 14. Oesophageal endoscopy in a dog showing the typical appearance of a S. lupiassociated oesophageal sarcoma. Note the roughened surface, necrotic grey-green colour and surface haemorrhages.

The results of endoscopically performed biopsies are disappointing. In early nodules, the intact stratified squamous epithelium of the oesophageal mucosa resists biopsy efforts. In the larger, more cauliflower-like lesions, where the possibility of neoplastic transformation may alter treatment strategies, the biopsy often does not include diagnostic tissue. Dvir et al. (2001) showed that of 13 endoscopic biopsies taken, eight showed only necrotic tissue on histopathology, whereas on later necropsy evidence two of those proved to be osteosarcomas. Successive biopsies from the same site are recommended to obtain deeper-lying tissue to maximise diagnostic information. The use of alpha agonist as pre-medication for the above mentioned procedures should be avoided. The alpha-agonist, medetomidine, has been incriminated in a single case as the cause of rupture of the compromised aorta due to the transient increase in peripheral vascular tone it precipitates (Joubert et al., 2005)

\section{Treatment}

\section{Medical treatment}

Over the years a number of different drugs have been used for treatment and or prophylaxis but to date no one remedy has been effective in killing both adult and larval stages of $S$. lupi while being devoid of host side-effects. Diethylcarbamazine, a piperazine derivative, was the first anthelmintic used for the treatment of spirocercosis 
and was shown to be effective in ameliorating the typical clinical signs of vomiting and regurgitation in animals with oesophageal nodules and improving the overall health status of the animal ([MacGaughey, 1950] and [Tacal, 1963]). While this drug was definitely of clinical benefit, it only suppressed egg shedding but did not affect the adult worm (Seneviratna et al., 1966). Disophenol, a substituted phenol, killed adult worms in nodules at a dose of $7.7 \mathrm{mg} / \mathrm{kg}$. The treatment was repeated after 7 days if poor clinical response was noted (Darne and Webb, 1964). The drug was not, however, effective against juveniles and had a narrow margin of safety and is no longer available (Seneviratna et al., 1966). A combination of nitroxynil $(10 \mathrm{mg} / \mathrm{kg}$ ) and ivermectin $(1000 \mu \mathrm{g} / \mathrm{kg})$ administered subcutaneously was reported to be successful in treating infected dogs in Reunion in $81.6 \%$ of cases. Clinical cure was concluded in animals following both endoscopic and faecal flotation evaluation (Reche-Emont et al., 2001). More recently, the cattle anthelmintic doramectin, a macrocyclic lactone, was shown to have good efficacy under clinical conditions. Dectomax ${ }^{\circledR}$ is $1 \%, \mathrm{~m} / \mathrm{v}$, solution of doramectin in a non-aqueous vehicle of sesame seed oil and ethyl eloate. Its use to treat $S$. lupi is extra-label as it is only licensed for use in cattle, pigs and sheep. Although highly lipophilic, doramectin has a relatively short half-life of $3.09 \pm 0.99$ and $3.75 \pm 0.89$ days, following subcutaneous and oral administration, respectively, with a mean tissue residence time of approximately 5 days (Gokbulut et al., 2006).

Safety trials performed by the manufacturers of Dectomax in beagles involved treating dogs per os with the sesame seed solvent formulation of doramectin at $0,500,1000$ and $2000 \mu \mathrm{g} / \mathrm{kg}$ per day for 91 days. Although the adverse effects were mild, transient, reversible and dose related in doses $\geqslant 500 \mu \mathrm{g} / \mathrm{mL}$, a no observable effect level (NOEL) of $500 \mu \mathrm{g} / \mathrm{mL}$ was assigned for the study (Conder et al., 2002). This was very similar to the result demonstrated for ivermectin during preclinical safety studies (Pulliam and Preston, 1989), with signs of reversible toxicity occurring at doses of $2500 \mu \mathrm{g} / \mathrm{kg}$ for single administration and $500 \mu \mathrm{g} / \mathrm{kg}$ following 2 weeks of daily dosing.

A specific breed specific toxicity has been reported to occur in collies and other herding dog breeds following the use of both ivermectin and doramectin ([Hopper et al., 2002] and [Yas-Natan et al., 2003]). Clinical signs reported included mydriasis, apparent blindness, muscle tremors and disorientation which eventually progresses to stupor and possible coma. In severe cases the clinical signs lasted approximately 22 days for both drugs, which tend to suggest a longer half-life of the macrocyclic lactones is this breed. The clinical signs in the milder toxicities usually resolve over a few days. More recently, it has been demonstrated that toxicity is related to a mutation in the MDR1-1 $\Delta$ gene and its ability to express the protective P-glycoprotein pump. This deficiency is reported to occur as a homozygous defect in $35 \%$ of Collies which corresponds to the species incidence of toxicity of $30 \%$ breed susceptibility ([Campbell, 1989] and [Mealey, 2006]). In the normal animal the P-glycoprotein pump is protective and is active in excluding certain drugs from the brain, decreasing oral bioavailability and increasing hepatic clearance of certain substances (Buxton, 2005).

Using a different protocol, Berry (2000) demonstrated that $200 \mu \mathrm{g} / \mathrm{kg}$ of doramectin injected SC at 14 day intervals for three subsequent treatments was effective in treating 
spirocercosis in 5/7 infected animals. Doramectin was again shown to be effective by Lavy et al. (2002) using an alternative dosing regimen of $400 \mu \mathrm{g} / \mathrm{kg}$, injected SC every 14 days for six treatments, followed by monthly dosing until resolution of the parasitic nodule. Eggs could not be detected in the faeces 3-10 days after the first treatment in four dogs and the second treatment in three dogs. The reduction in egg numbers was however immediate with a $99.3 \%$ decrease in egg numbers by the 10th day after first injection, suggesting a marked suppressive effect on egg production or shedding. Radiographic improvement after treatment, defined as resolution of the caudal mediastinal opacity occurred around 203 days after treatment (Lavy et al., 2002). Oesophageal nodules had completely resolved, as visualised endoscopically, between 35 and 544 days after treatment in 6/7 cases. Another study has also shown doramectin to be effective, but at a reduced treatment frequency of $500 \mu \mathrm{g} / \mathrm{kg}$ injected SC and repeated after 7 days. Egg counts performed daily showed no eggs from the fourth day after the second treatment (Kolte et al., 2001).

Most recently, Mylonakis et al. (2004) reported that only two doses of ivermectin at $600 \mu \mathrm{g} / \mathrm{kg}, \mathrm{SC}, 2$ weeks apart, in combination with oral prednisolone $(0.5 \mathrm{mg} / \mathrm{kg}$ bid for 2 weeks followed by dose tapering) promoted nodular regression in $5 / 8$ animals with natural $S$. lupi infection. Faecal egg shedding was eliminated in all eight animals for up to 2 months following the last treatment. This shortened dosage regimen was believed to result from the combination of two separate pharmacodynamic effects, the prednisolone promoting nodule regression and the ivermectin killing the parasite. However, it is not known if the same would not be true of a shortened dosage regimen in the original study by Lavy et al. (2002). It is our experience in South Africa that these smaller, smooth nodules are very responsive to medical treatment with doramectin utilising a variety of regimens, based on clinician preference.

With the pharmacokinetics of ivermectin and doramectin being described in dogs for both SC and oral administration, certain suppositions may be derived (Gokbulut et al., 2006). With both drugs being shown to have short half-lives of approximately 3 days following either oral or SC administration, this would suggest that dosing every 3-4 days may provide the prolonged exposure necessary to kill the parasite, i.e., instead of fortnightly dosing. From the presented area under the curve a relative oral bioavailability of $67 \%$ and $63 \%$ for ivermectin and doramectin, respectively was calculated as compared to the parenteral route and tends to suggest that oral dosing would require a $33 \%$ increase in dose to achieve the same exposure as parenteral treatment.

Similarities between Dirofilaria immitis (heartworm) infection and spirocercosis may suggest that similar treatment protocols could be effective, however, the differences between these two parasitic infections are many. The various dosages of the macrocyclic lactones reported as effective against $S$. lupi, are much higher than those for heartworm ([Campbell, 1989] and [McCall, 2005]). Another key difference appears to lie in the stage of life cycle, being treated with the macrocyclic lactones. Since the nodules contain the adult parasite and treatment with the macrocyclic lactones clearly indicates nodule resolution, it is a fair assumption that the drug is effective against the adults. This differs completely to heartworm were the adults are fairly resistant to the effect of the drug as 
seen with the prolonged time required for the macrocyclic lactones to eliminate adults (McCall, 2005).

With a large amount of the current drug efficacy data being based on a small sample size and extrapolations, it would be of value to determine the inhibitory dose for Spirocerca and use pharmacodynamic/pharmacokinetic modelling to determine the optimum dosage regime to treat this parasite (Sheiner and Steimer, 2000). Until this can be determined, it is dependent on the clinician to optimise treatment in the patient.

\section{Surgical and chemotherapeutic treatment}

Non-neoplastically transformed nodules will regress with medical treatment and some have been seen to regress spontaneously (Bailey, 1972). Surgery is therefore only required in cases where the nodules have undergone neoplastic transformation. In a report by Ranen et al. (2004), 10/15 patients with oesophageal sarcomas underwent surgery: six had partial oesophagectomies, two had oesophageal resection, one had a gastrostomy and one had a lesion too extensive to resect. The survival times in the six patients with the partial oesophagectomy and medical treatment with doxorubicin and doramectin averaged 267 days. The outcome for the cases with resection was very poor with the dogs surviving only 3 and 4 days, respectively.

Causes for the high complication rates in oesophageal surgery included excessive tension at the suture line, lack of serosa, constant motion of the suture site, passage of undigested food or saliva over the suture site, segmental blood supply and lack of omentum. Resection of $>3-5 \mathrm{~cm}$ increases the risk of dehiscence. Doxorubicin was prescribed as adjuvant anti-neoplastic therapy in five cases but no conclusions could be reached regarding the efficacy of the therapy. Carboplatin and doxorubicin in combination, or as mono-therapies, have improved survival in dogs with appendicular osteosarcoma after limb amputation, whereas fibrosarcomas are resistant to adjuvant chemotherapy (Straw, 2000). To date, there are, however, no data available on the effectiveness of chemotherapy in the treatment of spirocercosis-associated oesophageal sarcomas.

\section{Prevention}

Disease incidence can be reduced by disposal of faeces, preventing dogs from hunting, scavenging and eating uncooked viscera and decreasing egg shedding by infected animals. Control of coprophagous beetles and transport hosts is not a feasible form of control due to the variety and ubiquity of transport hosts in an endemic area.

A study by Lavy et al. (2003) to evaluate the prophylactic effect of doramectin showed that treatment at $400 \mu \mathrm{g} / \mathrm{kg}, 30$ days prior to exposure to infective larvae delayed the development of parasitic nodules in the oesophagus, resulted in fewer nodules and also subsequently delayed egg shedding by a minimum of 40 days in the treated group. Worm egg production in treated dogs was $97.7 \%$ less than the untreated group. The mean EPG in the treated group was $1.8 \pm 2.1$ and $101.9 \pm 102$ in the untreated group. This study, however, failed to address the question of ongoing prophylaxis in endemic areas, as the dogs were not treated again during the trial period nor were they further exposed to 
infective larvae. In reality, dogs from endemic areas would be continuously exposed to infective larvae. It would be of value to determine a minimum serum concentration required to inhibit or kill $S$. lupi adults and larvae and also the maximum treatment interval required to maintain this level. To date, all the macrocyclic lactones used to treat spirocercosis have been administered subcutaneously. The use of these compounds as an easily administered oral or topical preparation needs further investigation.

Preventative treatment should be aimed at maintaining patient health and decreasing environmental contamination. The dosing frequency to maintain optimal patient health would need to be more intense than that to decrease environmental contamination as worm migration in the aorta and larger arteries occurs early in infection and blood vessel rupture and acute death may occur in $2-12 \%$ of reported cases (Bailey, 1963).

\section{Conclusions}

Spirocercosis is a serious condition in endemic areas. Clinical signs usually develop late in the disease except in those cases presenting with peracute aortic rupture. Clinical signs, which should be regarded as highly suspicious for spirocercosis in endemic areas include vomiting or regurgitation, dyspnoea, persistent coughing and hypertrophic osteopathy. Radiological lesions regarded as diagnostic for spirocercosis in endemic areas are typical oesophageal nodules, aortic aneurysms and mineralisation and caudal thoracic spondylitis. Although endoscopy has a greater sensitivity for diagnosing spirocercosis, the importance of good quality radiographs should not be underestimated. Other secondary thoracic pathologies such as lung metastases, pneumonia, pleural effusion and mediastinitis may be detected radiologically and thus assist in the diagnostic process and the establishment of a prognosis. Thoracic radiographs made for non-spirocercosis related conditions, should be carefully scrutinised for radiological changes associated with spirocercosis to allow for early diagnosis and treatment of non-clinical cases in endemic areas.

Further studies are required to evaluate the efficacy of current macrocyclic lactone containing products. Even though the ideal dosage and dosing interval is not known, the intermittent use of doramectin should be advocated, not only to specifically prevent patient infection but also to decrease environmental contamination by eggs. A serological test to confirm S. lupi infection prior to the passage of eggs or the development of nodules could be helpful in endemic areas. Further work is also required on the biological behaviour and chemotherapeutic treatment modalities of the soft tissue sarcomas. Recent Israeli studies resulted in the establishment of a murine xenograft model of spirocerca associated sarcoma, thus establishing a readily available source of tumour cells for experimental purposes. Collaboration between the Universities and individuals studying the disease in the various endemic areas would facilitate more rapid understanding of the disease process. 


\section{References}

Alvarenga and Saliba, 1971 J. Alvarenga and A.M. Saliba, Iliac embolism in a dog, Modern Veterinary Practice 52 (1971), pp. 37-38.

Anataraman and Krishna, 1966 M. Anataraman and S. Krishna, Experimental spirocercosis in dogs with larvae from a paratenic host, Calotes versicolor, the common garden lizard in Madras, Journal of Parasitology 52 (1966), pp. 911-912.

Avner and Kirberger, 2005 A. Avner and R.M. Kirberger, The effect of the various thoracic radiographic projections on the appearance of selected thoracic viscera, Journal of Small Animal Practice 46 (2005), pp. 491-498.

Bailey, 1963 W.S. Bailey, Parasite and cancer: sarcoma in dogs associated with Spirocerca lupi, Annals of the New York Academy of Science 108 (1963), pp. 890-923.

Bailey, 1972 W.S. Bailey, Spirocerca lupi: a continuing inquiry, The Journal of Parasitology 58 (1972), pp. 3-22.

Bhatia et al., 1979 B.B. Bhatia, P.P.S. Chuahan, R.D. Agrawal and S.S. Ahluwalia, On helmintic infections of domestic duck and their pathogenic significance, Veterinary Research Bulletin 2 (1979), pp. 129-135.

Berry, 2000 W. Berry, Spirocerca lupi oesophageal granulomas in 7 dogs: resolution after treatment with Doramectin, Journal of Veterinary Internal Medicine 14 (2000), pp. 609-612.

Brodey et al., 1977 R.S. Brodey, R.G. Thompson, P.D. Sayer and B. Eugster, Spirocerca lupi infection in dogs in Kenya, Veterinary Parasitology 3 (1977), pp. 49-59.

Buxton, 2005 I.L.O. Buxton, Pharmacokinetics and pharmacodynamics: the dynamics of drug absorption, distribution, action and elimination. In: L. Brunton, J. Lazo, K. Parker, I. Buxton, D. Blumenthal, L.S. Goodman and A. Gilman, Editors, The Pharmacological Basis of Therapeutics, McGraw-Hill, New York (2005), pp. 1-40.

Cabrera and Bailey, 1964 D.J. Cabrera and W.S. Bailey, A modified Stoll technique for detecting eggs of Spirocerca lupi, Journal of the American Veterinary Medical Association 145 (1964), pp. 573-575.

Campbell, 1989 W.C. Campbell, Use of ivermectin in dogs and cats. In: W.C. Campbell, Editor, Ivermectin and Abamectin, Springer, New York (1989), pp. 245-259.

Chandrasekharon et al., 1958 K.P. Chandrasekharon, G.A. Sastry and M.N. Menon, Canine spirocercosis with special reference to the incidence and lesions, The British Veterinary Journal 114 (1958), pp. 388-395. 
Conder et al., 2002 G.A. Conder, W.J. Baker and C. Genchi, Chemistry pharmacology and safety: doramectin and selamectin. In: J. Vercruysse and R. Rew, Editors, Macrocyclic Lactones in Antiparasitic Therapy, CABI, New York (2002), pp. 30-50.

Coskun, 1995 S.Z. Coskun, Diagnosis of Spirocerca lupi by IFAT in naturally infected dogs, Turkiye Parazitoloji Dergisi 19 (1995), pp. 541-549.

Darne and Webb, 1964 A. Darne and J.L. Webb, The treatment of ancylostomiasis and of spirocercosis in dogs by the new compound 2,6-diiodo-4-nitrophenol, The Veterinary Record 76 (1964), pp. 171-172.

Dixon and McCue, 1967 K. Dixon and J.F. McCue, Further observations on the epidemiology of Spirocerca lupi in the south eastern United States, Journal of Parasitology 53 (1967), pp. 1074-1075.

du Plessis et al., in press du Plessis, C.J., Keller, N., Millward, I.R., 2007. Journal of Small Animal Practice, in press.

Dvir et al., 2001 E. Dvir, R.M. Kirberger and D. Malleczek, Radiographic and computed tomographic changes and clinical presentation of spirocercosis in the dog, Veterinary Radiology and Ultrasound 42 (2001), pp. 119-129.

Evans, 1983 L.B. Evans, Clinical diagnosis of Spirocerca lupi infestation in dogs, Journal of the South African Veterinary Association 54 (1983), pp. 189-191.

Fox et al., 1988 S.M. Fox, J. Burns and J. Hawkins, Spirocercosis in dogs, Compendium on Continuing Education for the Practicing Veterinarian 10 (1988), pp. 807-822.

Gal et al., 2005 A. Gal, S. Kleinbart, I. Aizenberg and G. Baneth, Aortic thromboembolism associated with Spirocerca lupi infection, Veterinary Parasitology 130 (2005), pp. 331-335.

Garg et al., 1989 U.K. Garg, S.B. Ghoshal, V.S. Richharia and K.S. Misraulia, An unusual occurrence of Spirocerca lupi worms in the heart of a dog, Indian Veterinary Journal 66 (1989), p. 1073.

Georgi et al., 1980 M.E. Georgi, H. Han and D.W. Hartrick, Spirocerca lupi (Rudolphi 1809) nodule in the rectum of a dog, Cornell Veterinarian 70 (1980), pp. 43-49.

Gokbulut et al., 2006 C. Gokbulut, U. Karademir, M. Boyacioglu and Q.A. McKellar, Comparative plasma dispositions of ivermectin and doramectin following subcutaneously and oral administration in dogs, Veterinary Parasitology 135 (2006), pp. 347-354.

Hamir, 1984 A.N. Hamir, Perforation of thoracic aorta in a dog associated with Spirocerca lupi infection, Australian Veterinary Journal 61 (1984), p. 64. 
Hamir, 1986 A.N. Hamir, Oesophageal perforation and pyothorax associated with Spirocerca lupi infestation in a dog, Veterinary Record 119 (1986), p. 276.

Harrus et al., 1996 S. Harrus, A. Harmelin, A. Markovics and H. Bark, Spirocerca lupi infection in the dog: aberrant migration, Journal of the American Animal Hospital Association 32 (1996), pp. 125-130.

Herrera and Ostrosky-Wegman, 2001 L.A. Herrera and P. Ostrosky-Wegman, Do helminths play a role in carcinogenesis?, Trends in Parasitology 17 (2001), pp. 172-175.

Hopper et al., 2002 K. Hopper, J. Aldrich and S.C. Haskins, Ivermectin toxicity in 17 Collies, Journal of Veterinary Internal Medicine 16 (2002), pp. 89-94.

Hu and Hoeppli, 1936 C.H. Hu and R.J.C. Hoeppli, The migration route of Spirocerca sanguinolenta in experimentally infected dogs, Chinese Medical Journal Supplement 1 (1936), pp. 293-311.

Johnson, 1992 R.C. Johnson, Canine spirocercosis and associated esophageal sarcoma, Compendium on Continuing Education for the Practicing Veterinarian 14 (1992), pp. 577-580.

Joubert et al., 2005 K.E. Joubert, M.J. McReynolds and F. Strydom, Acute aortic rupture in a dog with spirocercosis following administration of medetomidine, Journal of the South African Veterinary Association 76 (2005), pp. 159-162.

Kagira and Kanyari, 2001 J.M. Kagira and P.W.N. Kanyari, Parasitic diseases as causes of mortality in dogs in Kenya: a retrospective study of 351 cases (1984-1998), Israel Journal of Veterinary Medicine 56 (2001), pp. 11-99.

Kamara, 1964 J.A. Kamara, The incidence of canine spirocercosis in the Freetown area of Sierra Leone, Bulletin of Epizoology Diseases of Africa 12 (1964), pp. 465-469.

Klainbart et al., in press Klainbart, S., Mazaki-Tovi, M., Auerbach, N., Aizenberg, I., Bruchim, Y., Dank, G., Lavy, E., Aroch, I., Harrus, S. Spirocercosis-associated pyothorax in dogs. The Veterinary Journal, in press.

Kolte et al., 2001 S.W. Kolte, D.K. Maske and N.V. Kurkure, Treatment of Spirocerca lupi infection in dogs with doramectin, Journal of Veterinary Parasitology 15 (2001), p. 83.

Kumar et al., 1981a N. Kumar, J.L. Vegad and G.N. Kolte, Note on an unusual case of spirocerca granuloma in the stomach of a dog, Indian Journal of Animal Sciences $\mathbf{5 1}$ (1981), pp. 805-806.

Kumar et al., 1981b N. Kumar, J.L. Vegad and G.N. Kolte, Ossified lesions in canine aortic spirocercosis, Veterinary Record 109 (1981), pp. 142-143. 
Lavy et al., 2002 E. Lavy, I. Aroch, H. Bark, A. Markovics, I. Aizenberg, M. MazakiTovi, A. Hagag and S. Harrus, Evaluation of doramectin for the treatment of experimental canine spirocercosis, Veterinary Parasitology 109 (2002), pp. 65-73.

Lavy et al., 2003 E. Lavy, S. Harrus, M. Mazaki-Tovi, H. Bark, A. Markovics, A. Hagag, I. Aizenberg and I. Aroch, Spirocerca lupi in dogs: prophylactic effect of doramectin, Research in Veterinary Science 75 (2003), pp. 217-222.

Lobetti, 2000 R. Lobetti, Survey of the incidence, diagnosis, clinical manifestations and treatment of Spirocerca lupi in South Africa, Journal of the South African Veterinary Association 71 (2000), pp. 43-46.

Londono et al., 2003 N.Y. Londono, R.J.U. Carmona and M.C.E. Giraldo, Generalised osteosarcoma and secondary megaesophagus caused by Spirocerca lupi in a dog, Revista Colombiana de Ciencias Pecuarias 16 (2003), pp. 63-69.

Markovics and Medinski, 1996 A. Markovics and B. Medinski, Improved diagnosis of low intensity Spirocerca lupi infection by the sugar flotation method, Journal of Veterinary Diagnostic Investigation 8 (1996), pp. 400-401.

Mazaki-Tovi et al., 2002 M. Mazaki-Tovi, G. Baneth, I. Aroch, S. Harrus, P.H. Kass, T. Ben Ari, G. Zur, I. Aizenberg, H. Bark and E. Lavy, Canine spirocercosis: clinical, diagnostic, pathologic and epidemiologic characteristics, Veterinary Parasitology 107 (2002), pp. 235-250.

MacGaughey, 1950 C.A. MacGaughey, Preliminary note on the treatment of spirocercosis in dogs with a piperazine compound, caricide (Lederle), Veterinary Record 62 (1950), pp. 814-815.

Mealey, 2006 K.L. Mealey, Adverse drug reactions in herding breed dogs: the role of Pglycoprotein, The Compendium of Continuing Education - Small Animal Practice $\mathbf{2 8}$ (2006), pp. 23-33.

Mense et al., 1992 M.G. Mense, C.H. Gardiner, R.B. Moeller, H.L. Partridge and S. Wilson, Chronic emesis caused by a nematode induced gastric nodule in a cat, Journal of the American Animal Hospital Association 201 (1992), pp. 597-598.

McCall, 2005 J.W. McCall, The safety-net story about macrocyclic lactone heartworm preventives: a review, an update and recommendation, Veterinary Parasitology 133 (2005), pp. 197-206.

Minnaar et al., 2002 W.N. Minnaar, R.C. Krececk and L.J. Fourie, Helminths of dogs from a peri-urban resource limited community in Free State Province, South Africa, Veterinary Parasitology 107 (2002), pp. 343-349. 
Murray, 1968 M. Murray, Incidence and pathology of Spirocerca lupi in Kenya, Journal of Comparative Pathology 78 (1968), pp. 401-404.

Mylonakis et al., 2001 M.E. Mylonakis, A.F. Koutinas, M.V. Liapi, M.N. Saridomichelakis and T.S. Rallis, A comparison of the prevalence of Spirocerca lupi in three groups of dogs with different life and hunting styles, Journal of Helminthology 75 (2001), pp. 359-361.

Mylonakis et al., 2004 M.E. Mylonakis, T.S. Rallis, A.F. Koutinas, H.N. Ververidis and A. Fytianou, A comparison between ethanol-induced chemical ablation and ivermectin plus prednisolone in the treatment of symptomatic oesophageal spirocercosis in the dog: a prospective study on 14 natural cases, Veterinary Parasitology 120 (2004), pp. 131-138.

Nemanic et al., 2006 S. Nemanic, C.A. London and E.R. Wisner, Comparison of thoracic radiographs and single breath-hold helical CT for detection of pulmonary nodules in dogs with metastatic neoplasia, Journal of Veterinary Internal Medicine 20 (2006), pp. 508515.

Oliviera-Sequeira et al., 2002 T.G.C. Oliviera-Sequeira, A.F.T. Amarante, T.B. Ferrari and L.C. Nunes, Prevalence of intestinal parasites in dogs from Sao Paulo State, Brazil, Veterinary Parasitology 103 (2002), pp. 19-27.

Pereira et al., 1995 Pereira, W.L.A., Guimaraes, F.A.B., Martins, A.K.R., Peixoto, P.C., 1995. Haemopericardium in a dog associated with hyperparasitism by Spirocerca lupi. Boletim de Faculdade de Ciencias Agrarias do Para 23, 45-51.

Prunaux and Guignard, 1991 O. Prunaux and A. Guignard, Helminthoses of dogs on the island of Reunion: results at the department veterinary laboratory 1987-1990, Revue de Medecine Vétérinaire 142 (1991), pp. 757-760.

Pulliam and Preston, 1989 J.D. Pulliam and J.M. Preston, Safety of ivermectin in target animals. In: W.C. Campbell, Editor, Ivermectin and Abamectin, Springer, New York, USA (1989), pp. 149-161.

Rajan and Mohiyuddeen, 1974 A. Rajan and S. Mohiyuddeen, Incidence of spirocercosis in some uncommon sites, Kerala Journal of Veterinary Science 5 (1974), pp. 139-142.

Rallis et al., 1995 T.S. Rallis, K. Moraitou and J. Vlemmas, Gastroesophageal intussusception in an adult dog, Canine Practice 20 (1995), pp. 7-11.

Ramachandran et al., 1984 P.V. Ramachandran, S.A. Shakir and R. Ramakrishnan, Spirocercosis in canines - a necropsy survey, Cheiron Tamil Nadu Journal of Veterinary Science and Animal Husbandry 13 (1984), pp. 132-135.

Ranen et al., 2004 E. Ranen, E. Lavy, I. Aizenberg, S. Perl and S. Harrus, Spirocercosisassociated esophageal sarcomas in dogs. A retrospective study of 17 cases (1997-2003), Veterinary Parasitology 119 (2004), pp. 209-221. 
Reche-Emont et al., 2001 M. Reche-Emont, F. Beugnet and G. Bourdoiseau, Etude epidemiologique et clinique de la spirocercose canine a I'll de le Reunion a partir de 120 cas, Revue de Medecine Vétérinaire 152 (2001), pp. 469-477.

Ridgway and Suter, 1979 R.L. Ridgway and P.F. Suter, Clinical and radiographic signs in primary and metastatic oesophageal neoplasms of the dog, Journal of the American Veterinary Medical Association 174 (1979), pp. 700-704.

Schroeder and Berry, 1998 H. Schroeder and W. Berry, Salivary gland necrosis in dogs: a retrospective study of 19 cases, Journal of Small Animal Practice 39 (1998), pp. 121125.

Seibold et al., 1955 H.R. Seibold, W.S. Bailey, B.F. Hoerlein, E.M. Jordan and C.W. Schwabe, Observations of the possible relation of malignant esophageal tumours and Spirocerca lupi lesions in the dog, American Journal of Veterinary Research 16 (1955), pp. 5-14.

Sen and Anataraman, 1971 K. Sen and M. Anataraman, Some observations on the development of Spirocerca lupi in its intermediate and definitive hosts, Journal of Helminthology XLV (1971), pp. 123-131.

Seneviratna et al., 1966 P. Seneviratna, S.T. Fernando and S.B. Dhanapala, Disophenol treatment of spirocercosis in dogs, Journal of the American Veterinary Medical Association 148 (1966), pp. 269-274.

Sharpilo, 1983 V.P. Sharpilo, The reptiles of the USSR considered as intermediate and paratenic hosts of helminths, Parazitologiya 17 (1983), pp. 177-184.

Sheiner and Steimer, 2000 L.B. Sheiner and J.L. Steimer, Pharmacokinetic/Pharmacodynamic modeling in drug development, Annual Reviews in Pharmacology and Toxicology 40 (2000), pp. 67-95.

Singh et al., 1999 B. Singh, P.D. Juyal and V.K. Sobti, Spirocerca lupi in a subcutaneous nodule in a dog in India, Journal of Veterinary Parasitology 13 (1999), pp. 59-60.

Smith and Knottenbelt, 1989 D.A. Smith and D.C. Knottenbelt, Spirocerca lupi localisation in the spinal cord of a dog, Zimbabwe Veterinary Journal 18 (1989), pp. 1922.

Soulsby, 1982 E.J.L. Soulsby, Helminths, arthropods, and protozoa of domesticated animals, Lea and Febiger, Philadelphia, USA (1982) pp. 291-294.

Stephens et al., 1983 L.C. Stephens, C.A. Gleiser and J.H. Jardine, Primary pulmonary fibrosarcoma associated with Spirocerca lupi infection in a dog with hypertrophic pulmonary osteopathy, Journal of the American Veterinary Medical Association 182 (1983), pp. 496-498. 
Stettner et al., 2005 N. Stettner, E. Ranen, D. Dank, E. Lavy, I. Aroch, S. Harrus, O. Brenner and A. Harmelin, Murine xenograft model of Spirocerca lupi associated sarcoma, Comparative Medicine 55 (2005), pp. 510-514.

Straw, 2000 R.C. Straw, Bone and Joint Tumours. In: S.J. Ettinger and E.C. Feldman, Editors, Textbook of Veterinary Internal Medicine, Saunders, Philadelphia, USA (2000), pp. 535-540.

Tacal, 1963 J.V. Tacal, Dithiazanine iodide treatment for canine spirocercosis, Modern Veterinary Practice 44 (1963), pp. 70-73.

Thanikachalam et al., 1984 M. Thanikachalam, A. Sundararaj and R. Ramakrishnan, Cystitis associated with a nematode in a dog, Cheiron 13 (1984), pp. 220-222.

Tudury et al., 1995 E.A. Tudury, D.L. Graca and M.V.B. Arias, Spirocerca lupi induced acute myelomalacia in the dog. A case report, Brazilian Journal of Veterinary Research and Animal Science 32 (1995), pp. 22-26.

Upadhye et al., 2001 S.V. Upadhye, V.M. Dhoot and S.W. Kolte, Spirocerca infection in a tiger, Zoo's Print Journal 16 (2001), p. 450.

Wandera, 1976 J.G. Wandera, Further observations on canine spirocercosis in Kenya, The Veterinary Record 99 (1976), pp. 348-351.

Yas-Natan et al., 2003 E. Yas-Natan, M. Shamir, S. Kleinbart and I. Aroch, Doramectin toxicity in a collie, The Veterinary Record 153 (2003), pp. 718-720. 